\title{
LA EXCEPCIONAL AUTOTUTELA EJECUTIVA DE LOS ACTOS ADMINISTRATIVOS EN CHILE*
}

\author{
NiCOLÁS ENTEICHE RoSALES**
}

RESUMEN: El presente artículo analiza la autotutela ejecutiva o ejecución de oficio de los actos administrativos, en otras palabras la facultad de la Administración del Estado consistente en aplicar la coacción, ante el desobedecimiento de sus actos por un particular. Específicamente, esta investigación se aboca a responder, si es efectivo que en Chile existe una competencia genérica que permite a la Administración coaccionar a los destinatarios de sus actos, que se resisten a cumplirlos; con el anterior objeto se estudia la teoría del derecho, la Constitución, y la Ley $\mathrm{N}^{\circ} 19.880$. Una vez demostrada la inexistencia de la potestad genérica, este trabajo da cuenta y critica el modo en que diversas leyes concretan la autotutela ejecutiva en Chile, como atribuciones específicas a ciertos órganos administrativos para aplicar la coacción.

PALABRAS CLAVE: Autotutela administrativa - acto administrativo desfavorable - acto administrativo - coacción administrativa - Derechos Fundamentales - Constitución.

\section{THE EXCEPTIONAL POWER OF SELF-COMPULSION BY THE ADMINISTRATION TO ENFORCE ITS ACTS IN CHILE}

ABSTRACT: The present article analyses the power of self-compulsion by the Administration to enforce its acts in face of the resistance by an individual. In particular, this research addresses the issue of whether there is under Chilean law a generic power which allows the Administration to

\footnotetext{
Abreviaturas: Constitución Política de la República (“Constitución" o "CPR”), Código Orgánico de Tribunales (“COT”), Código de Procedimiento Civil (“CPC”), Código Procesal Penal (“CPP”), Código Civil (“CC”), Código Penal (“CP”), Código Tributario (“CT”), Código Sanitario ("CS"), Código del Trabajo (“CTra”), Código de Aguas (“CA").

Fecha de recepción: 19 de noviembre de 2013

Fecha de aceptación: 22 de mayo de 2014.

** Abogado, Profesor de Derecho Administrativo de la Universidad del Desarrollo (CHILe). El presente artículo forma parte de las publicaciones derivadas del proyecto "Acerca del acto administrativo, una delimitación conceptual", en el marco del concurso de fondos de investigación de la Universidad del Desarrollo, del año 2013. Agradezco la acuciosa labor de los ayudantes de investigación, Pilar Rodríguez y David Aranda. Correo electrónico: nenteicher@udd.cl
} 
force its acts upon a person that stands against them. To answer this question, this article draws from legal theory, the Constitution, and the Law $\mathrm{N}^{\circ} 19.880$. Once the inexistence of this generic power is demonstrated, this work turns to show and criticize the way followed by several laws to authorize the power of self-compulsion in Chile, as specific powers granted to certain administrative bodies to apply the force.

KEY WORDS: Administrative self-compulsion - unfavorable administrative acts - administrative act - administrative enforcement - Fundamental Rights - Constitution.

Sumario: Introducción. I. Delimitaciones conceptuales. 1. Efectos de las normas y reglas en Chile. 2. Ejecución de las reglas en Chile. 3. De la autotutela ejecutiva de los actos administrativos en Chile: una aproximación. II. De la autotutela ejecutiva de los actos administrativos en Chile: un análisis teórico. 1. ¿Qué actos administrativos podrian ejecutarse de oficio? 2. Inexistencia de una competencia genérica de autotutela ejecutiva de los actos desfavorables. III. De la autotutela ejecutiva de los actos administrativos en Chile: un análisis práctico. 1. La autotutela ejecutiva tiene lugar en virtud de excepciones legales 2. Aplicación práctica de la autotutela ejecutiva.

"La orden de un gangster, de entregarle cierta suma de dinero, tiene el mismo sentido subjetivo que la orden de un funcionario del Fisco... pero solo la orden del funcionario fiscal, y no la orden del gangster tiene el sentido de ser una norma válida que obligue al receptor; solo una y no la otra es un acto productor de una norma. Ello en cuanto la acción del funcionario fiscal se encuentra autorizada por una ley impositiva, mientras que el acto del gangster no reposa en ninguna norma que asi lo faculte" 1 .

Hans KELSEN

\section{INTRODUCCIÓN}

El presente artículo tiene por objeto analizar uno de los aspectos más complejos en la teoría del acto administrativo: la autotutela ejecutiva o el privilegio de la ejecución de oficio, esto es, la facultad que tendría la Administración del Estado, sin intermedio de un tercero y exceptuada de

Kelsen, Hans (1982) Teoría Pura del Derecho. Traducción de Roberto J. Vernengo. México D.F: Universidad Nacional Autónoma de México, p. 22. 
todo procedimiento, para ordenar la coacción, a fin de hacer cumplir sus decisiones.

Nuestro principal objetivo es dilucidar si es efectivo lo que alguna doctrina nacional ha sostenido con firmeza, que existe una potestad genérica de la Administración del Estado consistente en la atribución de coaccionar a un particular, luego de su resistencia a cumplir un acto administrativo, con el propósito de obtener su sumisión ante lo ordenado.

En un primer capítulo (1) acudiremos a la teoría del derecho, para entender el significado de la autotutela ejecutiva. Con la anterior finalidad (1.1-1.2) precisaremos que las reglas se ejecutan voluntariamente, o por orden de un juez, y (1.3) anticiparemos el criterio de parte de la doctrina administrativista, el cual excepcionando la anterior lógica, señala que las reglas emanadas de órganos administrativos -los actos administrativos- son "ejecutables de oficio" en virtud de la Ley No 19.880 .

En un segundo capítulo (2) desvirtuaremos la hipótesis doctrinaria antes aventurada, y mostraremos por qué, normativamente, la autotutela ejecutiva es una excepción. Para lograr lo anterior, (2.1) especificaremos cuáles actos administrativos son susceptibles de aplicación forzosa por la Administración, y (2.2) evaluaremos si su ejecución de oficio es la regla general o bien solo una excepción, de cara a la Constitución y a la Ley $\mathrm{N}^{\circ} 19.880$.

En un tercer capítulo (3) verificaremos cómo diversas leyes delimitan la real ejecución de oficio, y criticaremos su configuración. Al efecto (3.1) definiremos a la autotutela ejecutiva como aquellas excepciones legales que, en vista del desobedecimiento de un acto desfavorable o en virtud a una constatación por parte de un órgano administrativo, permiten aplicar la fuerza pública u otra medida de coacción, sin mediar procedimiento alguno, con el fin de satisfacer bienes jurídicos específicos.

Además de ejemplificar nuestra definición con casos formulados en las leyes, criticaremos al legislador. (3.2) También cotejaremos en la realidad práctica, si las mentadas competencias especiales de autotutela ejecutiva son, efectivamente, ejercidas por los órganos competentes. Por último expondremos algunas conclusiones.

\section{1) Delimitaciones CONCEPTUALES}

Antes de abocarnos a definir qué se entiende y cuál es el alcance de la autotutela ejecutiva o ejecución de oficio -términos que utilizaremos indistintamente- de los actos administrativos (1.1) creemos necesario delimitar algunas nociones propias de la teoría del derecho. Las anticipadas ideas son esenciales para comprender el contexto en cual cabe analizar (1.2) el modo en que se ejecutan las reglas jurídicas, (1.3) siendo parte de ellas, los actos administrativos. 


\section{1) EFECTOS DE LAS NORMAS Y REGLAS EN CHILE}

Una de las características de las fuentes formales del derecho es que existen al introducirse en el ordenamiento jurídico, pues solo ocurrida tal condición imperan, obligan, pueden exigirse y luego ejecutarse. La anterior afirmación, no obstante su sencilla formulación, presenta aspectos que debemos precisar.

Desde un prisma kelseniano, tanto las normas - preceptos generales y abstractos- como las reglas - preceptos particulares y concretos-, están vinculadas mediante un proceso de concreción y derivación normativo ${ }^{2}$, (1.1.1) y poseen rasgos comunes, entre estos está el momento en que nacen, imperan, obligan y son exigibles, (1.1.2) pero se distinguen en cuanto al modo en que se ejecutan.

1.1.1) Las normas y reglas nacen desde que se incorporan al sistema jurídico, esta inserción tiene lugar al momento de su comunicación a sus respectivos destinatarios. Por lo anterior la Constitución o una Ley -artículo 75 constitucional, u $8^{\circ}$ del CC-, se incorporarán a la vida del derecho una vez que se publiquen, y las reglas, como una resolución judicial, cuando se notifiquen -artículo 38 del CPC-.

Ocurrido el nacimiento, las proposiciones prescriptivas contenidas en una norma ${ }^{3}$-como aquellas emanadas del legislador-, o en una regla -como aquellas emanadas de un acto administrativo singular-, producirán los efectos que en ellas se disponga, salvo que en estas se determine que obligarán de modo retroactivo o diferido en el tiempo.

Así, la producción de los efectos de las normas o reglas, se iguala a la innovación que ocasionan en el ordenamiento jurídico. Denominamos a lo anterior imperatividad, y es a su propósito que se modificará la esfera jurídica de sus receptores, obligándolos y haciendo exigibles las prescripciones que ahí se contienen. Por la imperatividad, entonces, existe la obligatoriedad y la exigibilidad.

1.1.2) Ahora bien, una cosa es que una norma o regla nazca, obligue y sea exigible, y otra muy distinta es que, ante el incumplimiento de su contenido un sujeto pretenda forzar a otro, sin intermedio de un juez, a llevarlo a cabo. Lo anterior se explica pues la ejecución de las normas y reglas es temporalmente posterior a la imperatividad, y a su consecuente obligatoriedad y exigibilidad.

Kelsen (1982) 243-254; Bоввio, Norberto (1987) Teoría General del Derecho. Traducción de Eduardo Rozo Acuña. Bogotá: Editorial Temis, pp. 161-165.

A diferencia de otras normas que, ya sea por la fuente en que se contienen, el sujeto emisor de ellas, o porque solo conllevan un consejo, no obligan, confrontar con Bоввіо (1987) 39-66. 
Al hablar de ejecutar entendemos que se pretende "poner por obra algo", esto implica llevar a la realidad práctica un enunciado que se encuentra formulado de modo abstracto. En el caso de las fuentes del derecho, la ejecución es distinta si esta se refiere a normas o a reglas.

En el caso de las normas, su ejecución dice relación con la creación de una nueva, por un intérprete de estas. El intérprete de la norma $-y$, a su vez, creador de una nueva, más particular- elaborará una prescripción normativa cuyo contenido solo vinculará a sus destinatarios, en virtud del proceso de concreción regulatoria ${ }^{4}$, mediante una regla.

Distinto es el caso de la ejecución de una regla. Al constituirse estas en el último eslabón de la cadena de creación normativa, y ser inútil continuar creando nuevo derecho, la ejecución se referirá a su aplicación a la realidad práctica. La anterior materialización puede darse espontáneamente, o bien a través de medios coactivos -mediante la orden directa a la fuerza pública por un órgano estatal, u otro modo análogo- ${ }^{5}$.

\section{2) EJECUCión DE LAS REgLAS EN CHILE}

Por lo anterior, y siendo que un aspecto común entre normas y reglas es su imperatividad, obligatoriedad y exigibilidad, y que un elemento diferenciador entre ambas es el modo en que ocurre su ejecución, es útil ocuparnos acerca de cómo se aplican las reglas jurídicas en Chile, especialmente aquellas que innovan en el ordenamiento jurídico subjetivo ${ }^{6}$.

En otras palabras, nos interesa determinar cómo se materializan en la práctica las prestaciones contenidas en las siguientes reglas: resoluciones judiciales, convenciones y actos administrativos. Anticipándonos al análisis concluiremos que, en general, es la voluntad del destinatario, y subsidiariamente la orden de un juez, la forma en que se podrán llevar a cabo las prestaciones a las que obliga una regla.

La primera regla en análisis son las decisiones emitidas por los tribunales de justicia, contenidas en resoluciones judiciales. Las resoluciones de los tribunales se cumplen voluntariamente por sus destinatarios y, solo en caso que estos desatiendan su contenido, se hacen cumplir por el mismo u otro juez, quien coaccionará al desobediente.

Así queda claro al observar el artículo 11 del COT, el cual atribuye a los tribunales la competencia de requerir a la fuerza pública o aplicar

Rodríguez Grez, Pablo (1999) El Derecho Como Creación Colectiva. Santiago: Ediciones Jurídicas, pp. 221-222.

$5 \quad$ Estos actos de fuerza no son propiamente actos de producción de derecho Kelsen (1982) 244.

6 Las reglas pueden contener declaraciones enunciativas o decisiones, las primeras no ocasionan que se altere de forma inmediata la realidad-como por ejemplo lo será un testamento en que se exprese el afecto por alguien, o bien un acto administrativo en el que certifique un determinado hecho-, las segundas, con el solo mérito de su inserción al ordenamiento jurídico, provocan un cambio en la esfera subjetiva de sus destinatarios. 
cualquier otro medio de acción "para hacer ejecutar sus sentencias y para practicar las actuaciones que decreten", la antedicha afirmación es una regla general que trasunta el procedimiento civil y penal, respecto de toda clase de actos judiciales.

Se sigue la descrita disposición en materia procedimental civil, ya que el incumplimiento de los autos faculta a los tribunales para proveer "lo que convenga para la prosecución del juicio" - artículo 78 del CPC-. De igual manera, la insubordinación a sentencias definitivas e interlocutorias firmes da pie para su cumplimiento judicial -artículo 176 del CPC-. Por último, en materia procesal penal también existe el poder coactivo en la ejecución de las resoluciones -artículo 34 del CPP-.

De igual forma, los consensos entre partes, traducidos en convenciones, tienen como finalidad que los sujetos que concurren a su perfeccionamiento cumplan de modo espontáneo las obligaciones que contraen ${ }^{7}$, y en caso de que estas se desconozcan, solo un juez podrá ordenar que se realicen de modo compulsivo -artículo 1.489 del CC- ${ }^{8}$.

¿Qué señala el ordenamiento jurídico respecto de las decisiones de la Administración del Estado? ¿Es el juez quien puede, por regla general, aplicar los actos administrativos que no son cumplidos por sus destinatarios, o existe una disposición diversa?

\section{3) DE LA AUTOTUTELA EJECUTIVA DE LOS ACTOS ADMINISTRATIVOS EN CHILE: UNA APROXIMACIÓN}

La respuesta aparecería en la Ley No 19.880. La precitada norma incorpora, en su Capítulo I, titulado “disposiciones generales”, un artículo $3^{\circ}$ referido al "concepto del acto administrativo", el cual, en su inciso octavo, versa acerca de los efectos de los actos administrativos.

El precepto señala, en lo relevante, que "los actos administrativos gozan (...) de imperio y exigibilidad frente a sus destinatarios, desde su entrada en vigencia, autorizando su ejecución de oficio por la autoridad administrativa, salvo que mediare una orden de suspensión dispuesta por la autoridad administrativa dentro del procedimiento impugnatorio o por el juez, conociendo por la vía jurisdiccional".

De esta forma, la Ley No 19.880 enuncia a través de tres verbos rectores los efectos y el modo de ejecución de los actos administrativos:

\footnotetext{
7 Debemos partir por la premisa que la coacción es innecesaria "porque debemos partir del principio -al menos teórico y convenientemente estimulante- que los seres humanos cumplen habitualmente sus deberes jurídicos". Fueyo Laneri, Fernando (2004) Cumplimiento e incumplimiento de las obligaciones. $3^{a}$ edición. Santiago: Editorial Jurídica de Chile, p. 270.

8 "El órgano del Estado llamado a imponer el cumplimiento es el Poder Judicial; a los tribunales debe recurrir el acreedor en amparo de su derecho al cumplimiento" Abeliuk MaNASEVICH, René (2005) Las obligaciones. 4a edición, Santiago: Editorial Jurídica de Chile, Tomo II, p. 713.
} 
los actos tendrán imperio y serán exigibles, además podrán ejecutarse de oficio desde su entrada en vigencia. Vistos preliminarmente, podríamos conjeturar que las precitadas expresiones conforman expresiones análogas; empero un breve análisis aclara lo contrario.

Es a partir de la entrada en vigencia, esto es el momento en que la regla administrativa obliga, que se da pie a la imperatividad y exigibilidad, en virtud de las cuales la Administración del Estado, al emitir un acto que contenga una decisión, creará unilateralmente relaciones jurídicas entre ella y otro sujeto de derecho?

A continuación, pareciendo indisolublemente concatenado a la imperatividad y exigibilidad, la Ley No 19.880 autoriza a que la Administración del Estado ejecute o ponga en práctica de oficio y de modo forzoso, los actos que ya emitió ${ }^{10}$.

La idea de ejecución de oficio como una competencia genérica de la Administración del Estado, para ordenar forzar al destinatario desobediente es abonada por ciertos autores, antes y después de la entrada en vigencia de la Ley $\mathrm{N}^{\circ} 19.880$. Sus razones se exponen a continuación.

Antes de la existencia de la Ley $\mathrm{N}^{\circ} 19.880$, algunos se apoyaban en la naturaleza del acto administrativo, en la presunción de legalidad, o bien en alguna doctrina extranjera para afirmar tal cuestión -véase a Patricio Aylwin ${ }^{11}$, Sergio Aranis ${ }^{12}$, Hugo Calde-

9 Los autores han dicho respecto de la imperatividad, que su sentido es "crear, modificar o extinguir derechos y obligaciones, de modo directo e inmediato, real y concreto, sin el acuerdo o consentimiento de quienes van a ser afectados por tal prescripción" Soto KLoss, Eduardo (1978) La ejecución del acto administrativo (Suspensión y revocación). Bogotá: Colegio Mayor de Nuestra Señora del Rosario, p. 7; también se ha dicho que es aquel "poder de la administración de crear unilateralmente relaciones jurídicas con otros sujetos y que se traduce en actos administrativos que, entre otros efectos, pueden alterar favorable o desfavorablemente la situación jurídica de esos terceros, sin necesidad de su consentimiento" Aróstica Maldonado, Iván (1995) Lecciones Sobre Acto Administrativo. Santiago: Inédito/ Facultad de Derecho de Universidad de Chile, Departamento de Derecho Público, p. 77.

10 No profundizaremos en distinguir los conceptos con que los autores se han referido a la aplicación forzosa, por la Administración del Estado de los actos administrativos singulares. Algunos la denominan "ejecutoriedad", otros "acción directa", para nosotros esto corresponde a lo que ya denominamos "ejecución de oficio" o "autotutela ejecutiva”.

11 "En Derecho Administrativo, los actos tienen en sí mismos fuerza ejecutiva. La situación jurídica por ellos creada, modificada, reconocida o extinguida puede ejecutarse con el solo mérito del acto administrativo y sin intervención de la autoridad judicial. No hay solución de continuidad entre el acto y su ejecución” Aylwin Azócar, Patricio (1952) Manual de Derecho Administrativo. Santiago: Editorial Jurídica de Chile, p. 158.

12 "El acto administrativo (...) procediendo subjetivamente de la Administración (que posee potestad pública), impone directamente su cumplimiento sin trabas de ninguna especie impone directamente su cumplimiento sin trabas de ninguna especie, dedo su poder para hacer cumplir objetivamente sus resoluciones, propiedad esta del acto administrativo". Aranis Merino, Sergio (1955) El principio de la ejecutoriedad del acto administrativo. Memoria de Prueba para optar al grado de Licenciado en Ciencias Juridicas y Sociales. Santiago: Editorial Universitaria S.A., p. 50. 
ra $^{13}$, Gladys Camacho ${ }^{14}$, Guillermo Iribarren ${ }^{15}$, Manuel Jara ${ }^{16}$, Mónica Madariaga ${ }^{17}$, Osvaldo Oelkers ${ }^{18}$, Enrique Silva Cimma ${ }^{19}$ y Carlos Urzúa ${ }^{20}$.

Luego de la entrada en vigencia de la Ley No 19.880, Eduardo Cordero, a propósito del artículo $3^{\circ}$ inciso octavo, señala que "nuestro Derecho positivo atribuye a la Administración una potestad genérica para

13 "La ejecutoriedad consiste en la facultad de que dispone la Administración ante el incumplimiento de las obligaciones o cargas impuestas por un acto administrativo a un administrado, para adoptar una de las siguientes medidas (...) multa (...) hacer ejecutar el acto por sus propios medios, es decir con elementos que le pertenecen orgánicamente, por cuenta y cargo del administrado renuente (...) hacer cumplir el objeto del acto por medio de un tercero ajeno a la Administración (....)" Caldera Delgado, Hugo (1981) El Acto Administrativo: Legalidad, efectos e impugnación. Santiago: Editorial Juridica de Chile, p. 76.

14 "En virtud de la potestad de autotutela la Administración a través de sus órganos competentes, en cada caso podrá proceder a la ejecución forzosa de los actos administrativos, salvo en los supuestos en que se haya dispuesto la suspensión de la eficacia de los mismos o la ley expresamente determine otra forma de ejecución" CAмAcho, Gladys (2002) El Acto Administrativo. Santiago: Facultad de Derecho de Universidad de Chile, Departamento de Derecho Público, p. 33.

15 La ejecutoriedad, señala "consiste en que entre la manifestación de voluntad y su realización no existe solución de continuidad jurídica” y agrega "la ejecutoriedad se manifiesta, además, porque opera sin intervención de otro poder (...)” Iribarren, Juan Antonio (1936) Lecciones de Derecho Administrativo. Santiago: Editorial Nascimento, p. 38.

16 "Todo acto administrativo tiene la propiedad de ser esencialmente ejecutivo, por proceder de la administración, y con independencia de que se ejecute o no, lo cual puede depender de la decisión de la misma administración o de una orden jurisdiccional”. JARA Cristi, Manuel (1943) Derecho Administrativo. Santiago: Impresores "Artes y Letras", p. 235.

17 Quien señala, haciendo suya doctrina extranjera que cita, que el acto administrativo posee el carácter de la ejecutoriedad "por la "presunción de regularidad jurídica o legitimidad" de los actos administrativos, lo cual significa que tales actos deben cumplirse, por cuanto se presume que son legítimos por emanar de una autoridad pública regularmente constituida”. MADariaga Gutiérrez, Mónica (1965) Derecho Administrativo y Seguridad Jurídica. Santiago: Editorial Jurídica de Chile, p. 63. Respecto de esta autora es necesario hacer un matiz, pues ya en el año 1965 hizo una escisión en cuanto a los actos que eventualmente sería aplicables mediante la coacción, así dejó fuera de la argumentada facultad general de aplicar coactivamente todos los actos desfavorables a "aquellos en los que los efectos que deben producir van implícitos en su contenido” Madariaga (1965) 61.

18 "La ejecución forzada consiste en la potestada (sic) concedida a la Administración para utilizar su propia coacción con el objeto de dar cumplimiento a sus actos”. Oelkers Camus, Osvaldo (1978) "El principio de la autotutela administrativa como privilegio de la Administración Pública”. Revista de Derecho de la Universidad Católica de Valparaíso, N², p. 134.

19 "Hay un efecto consustancial al acto administrativo: la ejecutoriedad. El acto se ejecuta por la Administración sin recurrir a otros poderes. En cambio, en el Derecho Común la ejecución de los actos que celebran los particulares corresponde a los tribunales ordinarios. La Administración puede ejecutar el acto que emane de ella misma. El principio de la ejecutoriedad es de la esencia del acto administrativo”. Silva Cimma, Enrique (2001) Derecho Administrativo Chileno y Comparado: actos, contratos y bienes. Santiago: Editorial Jurídica de Chile. Volumen V, p. 102.

20 "El acto administrativo tiene desde su nacimiento una fuerza ejecutiva que da a la Administración la facultad de proceder a lo que se llama "acción directa", es decir, "que el acto es ejecutivo por el solo hecho de que ha sido emitido". Lo ejecuta la propia administración y corresponde a lo que conocemos como ejecutoriedad del acto" Urzúa Ramírez, Carlos (1971) Requisitos del Acto Administrativo. Santiago: Editorial Juridica de Chile, p. 24. 
proceder a la ejecución forzosa de sus actos. Así lo establece el ya citado inciso final del art. 3 LBPA (...)"21.

Entonces, de acuerdo a los precitados autores ¿cuál es el sentido de la frase "autorizando su ejecución de oficio por la autoridad administrativa", formulada en la Ley No 19.880? La oración significa que la Administración del Estado luego de emitir un primer acto administrativo de cualquier especie podría aplicarlo a la realidad, a través de cualquier medio, inclusive mediante la coacción ${ }^{22}$ al destinatario desobediente.

Así, de improviso, el Derecho Administrativo se excepcionaría de la lógica tras de la ejecución de las reglas, ya que: las resoluciones judiciales y las convenciones se ejecutarían voluntariamente o, tras su incumplimiento, previa orden de un juez, empero los actos administrativos se podrían coaccionar, ante el desobedecimiento del destinatario, por la sola orden de la Administración del Estado.

¿Es la ejecución de oficio de todos los actos administrativos en Chile una ilusión o la realidad? Una visión doctrinaria, a partir del artículo $3^{\circ}$ inciso octavo de la Ley No 19.880, plantea que sí. Mas creemos que antes de las apariencias y opiniones, es necesario un meditado análisis.

\section{2) De la aUtotutela eJECUTIVA De los aCtOS ADMinistrativos EN CHILE: UN ANÁLISIS TEÓRICO}

La ejecución de la reglas, dijimos, consiste en su aplicación práctica a la realidad por medios coactivos, cuando su destinatario no las cumple voluntariamente. En el caso del acto administrativo, agregamos, el artículo $3^{\circ}$ inciso octavo de la Ley No 19.880, más alguna doctrina, nos haría concluir que la ejecución de oficio es la regla general en el Derecho Administrativo chileno.

(2.1) Creemos adecuado, antes de suscribir tal o cual regla general, delimitar los actos administrativos que podrían ser objeto de autotutela ejecutiva, para luego (2.2) analizar el ordenamiento jurídico. Solo a través de la anterior fórmula podremos concluir si la Administración del Estado puede ordenar de forma general, la coacción de los actos desobedecidos por sus receptores.

21 Cordero Quincazara, Eduardo (sin fecha) La eficacia, extinción y ejecución de los actos administrativos en la ley No19.880. En: Escuela de Derecho Universidad Católica de Valparaíso: Actas de las segundas jornadas de Derecho Administrativo. Santiago: Ediciones Universitarias de Valparaíso, p. 127.

22 El término preciso es este y no coerción, toda vez que los medios utilizados, como lo es la orden directa a la fuerza pública para su cumplimiento u otro análogo, tienen como finalidad que se ejecute la voluntad de la Administración. En el caso de la coerción, la finalidad de los medios utilizados es forzar la voluntad del sujeto forzado, cuyo no es el caso de la ejecución del acto administrativo. 


\section{1) ¿QUÉ ACTOS ADMINISTRATIVOS PODRÍAN EJECUTARSE DE OFICIO?}

Solo las decisiones singulares, que perjudiquen a un particular y en el supuesto que este se niegue a cumplirlas serían susceptibles de ser ejecutadas por la fuerza. De ahí que la ejecución de oficio, como competencia genérica para ser aplicada a todos los actos administrativos, merezca ser acotada. Lo postulado se desarrolla a continuación.

Ciertos actos administrativos agotan sus efectos con su solo nacimiento a la vida jurídica -desde su notificación o publicación-, otros requieren para ponerse en práctica de una segunda manifestación de voluntad. Lo antedicho se explica al tener en vista cómo se clasifican los actos administrativos, en razón de su objeto.

De acuerdo a la Ley No 19.880, los actos administrativos pueden contener las siguientes manifestaciones de voluntad: las que declaran decisiones, y se contienen en decretos o resoluciones -artículo $3^{\circ}$, inciso primero y tercero-, las de juicio, que declaran opiniones, y se concretan en dictámenes, y las de conocimiento, que declaran constancias, y aparecen en certificados -artículo $3^{\circ}$, inciso sexto- ${ }^{23}$.

Los únicos actos administrativos que son susceptibles de aplicación coactiva, son aquellos que manifiestan una voluntad -en adelante, "actos decisorios"-. Así, otras manifestaciones, que no signifiquen una declaración de voluntad, como aquellas tendientes a certificar o interpretar, no son susceptibles de ejecución de oficio.

Lo anterior se debe a un criterio residual, dado que por este se descarta la aplicación coactiva de los actos administrativos, (2.1.1) que no modifiquen la esfera jurídica subjetiva de sus destinatarios, (2.1.2) y de aquellos que, aún alterándola, se concretan de un modo diverso al forzoso.

2.1.1) Los actos decisorios que tienen por objeto innovar en el ordenamiento jurídico objetivo -en otras palabras, las normas emitidas por la Administración-, y los actos que no contienen una decisión, sino una declaración diversa -como la constatación de un hecho o una respuesta negativa-, no pueden ejecutarse de oficio.

En el caso de los actos decisorios que innovan en el ordenamiento jurídico objetivo, conocidos como reglamentos o actos administrativos

23 Esta clasificación no es propia de la Ley $\mathrm{N}^{\circ} 19.880$, sino que connota las vías mediante las que, tradicionalmente, se escinden las diversas declaraciones que pueden pronunciar sus órganos. La doctrina administrativa chilena recoge esta clasificación uniformemente, véase Silva Cimma (2001) pp. 82-97; Pantoja Bauzá, Rolando (1960) Concepto de Acto Administrativo. Santiago: Editorial Jurídica de Chile, p. 87 y más recientemente Aróstica (1995) 16-18, y Moraga Klenner, Claudio (2010) Tratado de Derecho Administrativo: La actividad formal de la administración del Estado. Santiago: Editorial LegalPublishing, p. 108, por solo nombrar algunos. 
generales, al ser normas y no reglas jurídicas -véase capítulo I, punto 1-, si bien formalmente su finalidad se basta al entrar en vigencia, les resta para ser aplicados concretarse e identificar a sus destinatarios, por lo que no serán susceptibles de ser coactivamente impuestos ${ }^{24}$.

De igual modo, existen actos que aún dirigiéndose a algún destinatario específico, poseen un objeto que no es posible de ser aplicado por un segundo acto coactivo, por lo que se descarta su ejecución de oficio. Es el caso de aquellos actos que se aplican de inmediato, sin la necesidad de una segunda voluntad, por lo cual gozan de imperatividad propia ${ }^{25}$.

Dentro de la categoría de actos propiamente imperativos están los que tienen por objeto comprobar la existencia de un hecho, denominados en doctrina certificatorios; corresponden al mismo género los actos que niegan una solicitud de un particular, llamados actos denegatorios.

En el caso de los actos certificatorios, será suficiente la voluntad declarada en un acta por un Carabinero ${ }^{26}$ o un Inspector del Trabajo ${ }^{27}$, quienes, a modo de ejemplo, acreditan la velocidad de un vehículo, o la situación fáctica de los trabajadores, respectivamente. En cuanto a los actos denegatorios, la notificación de la repulsa es apta para su aplicación práctica.

2.1.2) Así, y de acuerdo a lo antes razonado, solo el contenido decisorio de los decretos o las resoluciones administrativas podrían ser ejecutados de oficio. En general, todos los actos decisorios requieren para ser aplicados, además de la voluntad de innovar en el patrimonio del sujeto a que afectan, de un segundo acto, de cumplimiento posterior ${ }^{28}$.

Ahora bien, en el caso que exista un primer acto decisorio de la Administración, que contenga la declaración de voluntad de innovar positivamente en el patrimonio de una persona -en adelante, "acto favorable"-, este se concretará mediante otro acto cuyo objeto será, en los hechos, la

24 Hacemos notar, eso sí, que existen normas emanadas de la Administración que no requieren de la mediación de un segundo acto singular para ser aplicadas. El anterior sería el caso, a modo de ejemplo, del Decreto de Fijación Tarifaria de Precio de Nudo Promedio, en virtud del cual se fija el precio promedio que las empresas concesionarias de servicio público de distribución deben traspasar a sus clientes -véase Decreto Supremo No 16, del Ministerio de Energía, de 2012-.

25 Soto KLoss (1978) 13-14.

26 Carabineros de Chile es competente para acreditar la ocurrencia de un hecho eventualmente constitutivo de una falta, lo que se determinará previa denuncia, por un Juzgado de Policía Local -artículo $4^{\circ}$, de la Ley No 18.287, "Ley del Tránsito" y el artículo 3º, de la Ley No 18.290 que "establece el procedimiento ante los Juzgados de Policía Local” respectivamente-. Los Inspectores del Trabajo pueden, al visitar los lugares de trabajo certifican hechos -artículos 23 al, 39 del DFL No 2, del Ministerio del Trabajo, de 1967, que "dispone la reestructuración y fija funciones de la Dirección del Trabajo"-.

28 En esta lógica no caben los actos administrativos decisorios, que facultan a realizar una actividad o ejecutar un hecho. Lo anterior se debe a que las autorizaciones o permisos no requieren de un segundo acto administrativo que ponga en práctica al primero. 
incorporación material al patrimonio del beneficiado de los bienes de los que es titular, en virtud del primer acto.

Este segundo acto se traducirá en la primera de las hipótesis de imperatividad impropia, pues el acto originalmente emitido se llevará a cabo, por medio de una segunda voluntad emitida, en este caso, por la Administración del Estado. Pero la segunda voluntad o acto secundario de ejecución, no consistirá en la aplicación de medios coactivos, sino que en la emisión de un decreto o resolución de pago -artículo 100 de la CPR-29.

Por ejemplo, en el caso que se otorgue, mediante un acto favorable, el "Premio Nacional de Literatura"30 o el "Bono Bodas de Oro"31, para concretar las prestaciones que tales reconocimientos conllevan, será necesario emitir un segundo acto que pague los beneficios reconocidos, los que serán emitidos en este caso por el Tesorero General de la República ${ }^{32}$, o por el Director de Instituto de Previsión Social ${ }^{33}$, respectivamente.

Por consiguiente, debemos descartar de la ejecución de oficio a los actos cuyo objeto es beneficiar o favorecer a un particular, puesto que se llevan a efecto a través de un segundo decreto o resolución, cuyo objeto será incorporar los bienes al patrimonio del beneficiado por el primer acto decisorio.

Excluidos de la aplicación de oficio los actos que no exteriorizan una voluntad cuyo objeto sea innovar en el ordenamiento jurídico subjetivo, y de aquellos que aún manifestándola benefician a su destinatario, solo nos resta abocarnos a la hipótesis en que un acto declare una decisión negativa o desfavorable para los derechos de sus destinatarios.

En el supuesto que un acto administrativo singular y decisorio, sea desfavorable para la persona a quien se dirige, solo podría ser aplicado

29 En caso que un decreto o resolución ordene determinadamente un pago, no necesitará de un segundo. La descrita hipótesis tiene lugar pues en los decretos o resoluciones contienen la expresión comuníquese, la que significa "comunicación a la Tesorería General, cuando se trate de compromisos para el Estado" -artículo 17, inciso primero, del DFL $N^{\circ} 7912$, de 1927, que "organiza las secretarías del estado"-, de no cumplirse la orden de pago por el funcionario destinatario de esta "perderá por este solo hecho su empleo" -artículo 17, inciso segundo, del DFL $\mathrm{N}^{\circ} 7912-$. El antes descrito sistema tiene su materialización para todo el sector público en el artículo 31, inciso segundo, del DL N 1263, de 1975, "Ley Orgánica de Administración Financiera del Estado".

30 El premio es concedido por un Jurado -artículo 9, de la Ley No 19.169, que "establece normas sobre otorgamiento de premios nacionales"- y consisten en la entrega de un diploma, más de una suma de dinero y una pensión vitalicia -artículo 17, Ley No 19.169-.

31 Se reconoce el cumplimiento de los requisitos para el otorgamiento del bono -artículo 1 de la Ley No 20.506, que "otorga un bono a los cónyuges que cumplan cincuenta años de matrimonio"-, por el Instituto de Previsión Social -artículo $4^{\circ}$ de la Ley No 20.506-.

32 El pago del beneficio que implica la concesión del Premio Nacional, lo efectúa la Tesorería General de la República, previa solicitud del Ministerio de Hacienda -artículo 43, del Decreto Supremo No 315, del Ministerio de Educación, de 2011, que reglamenta la Ley No 19.169-.

33 El pago del beneficio que acarrea el reconocimiento de las condiciones del "Bono Bodas de Oro", lo emite el Instituto de Previsión Social -artículo 5 de la Ley No 20.506, en relación con el artículo $7^{\circ}$ y siguientes del Decreto Supremo No 415, del Ministerio de Hacienda, de 2011, que reglamenta la Ley No 20.506-. 
coactivamente en caso que el sujeto destinatario de la manifestación de voluntad se niegue a cumplir su contenido -en adelante, los "actos desfavorables”-. Ahora bien, si existe la decisión de acatar la voluntad de la administración, entonces, no debería concretarse la autotutela administrativa.

Reducida la mentada competencia general de autotutela ejecutiva, solo a la ejecución de los actos administrativos decisorios desfavorables ¿será efectivo que, jurídicamente, la Administración del Estado pueda aplicar sus actos desfavorables coactivamente?

\section{2) INEXISTENCIA DE UNA COMPETENCIA GENÉRICA DE AUTOTUTELA EJECUTIVA DE LOS ACTOS DESFAVORABLES}

Como vimos, el artículo 3º, inciso octavo de la Ley No 19.880, más alguna doctrina, nos llevaría a concluir que en Chile la regla general es la autotutela ejecutiva, en otras palabras que la Administración del Estado, frente a la voluntad negativa de una persona a cumplir un acto desfavorable que pueda afectar sus derechos, puede aplicarlo por propia mano.

Creemos que a la inversa, en el caso de los actos administrativos y, específicamente, respecto del modo en que se concretan los actos desfavorables, existen cuerpos normativos superiores y generales que prescriben otra regla general: (2.2.1) la Constitución formula mandatos, que (2.2.2) la Ley No 19.880 concreta, al reconocer que solo los tribunales de justicia pueden aplicar por la fuerza los actos administrativos que afecten los derechos de su destinatarios, de modo que la heterotutela judicial pasa a ser la regla general.

2.2.1) La Constitución (a) dispensa expresamente la atribución para que el Poder Judicial aplique sus actos desfavorables, reforzando esta idea (b) las facultades excepcionales del Presidente de la República en los Estados de Excepción Constitucional, y (c) el modo en que se estructuran las competencias de otros relevantes organismos constitucionales.

a) La CPR, en su artículo 76, inciso tercero, entrega la competencia al Poder Judicial, puntualmente a "los tribunales ordinarios de justicia y los especiales", para "hacer ejecutar sus resoluciones", pudiendo estos para tal objeto, "impartir órdenes directas a la fuerza pública o ejercer los medios de acción que estimen conducentes" 34 .

34 Así queda en evidencia de la lectura de las Actas Constitucionales de la Comisión Constituyente de 1980, lugar en que se gestó el artículo 76. El sentido práctico del precepto es establecer constitucionalmente la facultad de imperio a los tribunales, y evitar así que el Poder Ejecutivo dilate la ejecución de sus resoluciones. Así aparece, por ejemplo, de la intervención del Ministro de la Corte Suprema, señor José María Eyzaguirre quien expresó que "la razón que se tuvo se origina en la necesidad de no estar sometido al visto bueno del Ministerio del Interior y de la intendencia. La finalidad es que los tribunales tengan un medio efectivo para hacer cumplir sus resoluciones" Comisión De Estudios de LA Nueva 
Así entonces, por disposición expresa, la Constitución otorga una competencia amplia - no acotada a materia ni persona alguna- al Poder Judicial, de aplicar coactivamente sus actos desfavorables. El medio dispuesto constitucionalmente para el anterior efecto es la aplicación de la fuerza u otras vías que los jueces ordenen, siempre que sean concurrentes a fin de aplicar una resolución judicial.

La facultad de aplicar por la fuerza sus resoluciones se encuentra indisolublemente unida a la jurisdicción y a sus momentos, como son los de conocer de todo conflicto de intereses entre los sujetos de derecho, y resolverlos. Por lo anterior, tanto conocer, como resolver, y ejecutar lo juzgado son facultades irrebatiblemente vinculadas y concedidas a los tribunales de justicia ${ }^{35}$.

Coherente con esta atribución, las propias leyes referidas a los tribunales de justicia -artículo 11, inciso primero del $\mathrm{COT}^{36}$, a Carabineros de Chile -artículo 4o , inciso primero de la Ley No $18.961^{37-38}$ - y a la Policía de Investigaciones de Chile -artículo $1^{\circ}$ del Decreto Ley $\mathrm{N}^{\circ}$ $2.460^{39}-$, individualizan en primer término a estos como los emisores de la orden de ejecución, y a los últimos como quienes la llevan a cabo.

b) Ratifica esta idea que la Constitución haya dispuesto en sus artículos 43 y 45, que el Presidente de la República puede aplicar actos que

Constitución (1977), Sesión Nº 301a , 28 de junio de 1977, p. 437 [Fecha de consulta: 27 de septiembre de 2013] Disponible en: http://www.bcn.cl/lc/cpolitica/constitucion_politica/Actas_comision_ortuzar/Tomo_IX_Comision_Ortuzar.pdf.

35 Se ha dicho que "en el sistema nuestro, el imperio se caracteriza por ser una facultad privativa del Poder Judicial" Casarino Viterbo, Mario (2007) Manual de Derecho Procesal, Derecho Procesal Orgánico. 6a edición. Santiago: Editorial Jurídica de Chile, p. 36 confrontar con Colombo Campbell, Juan (1991) La Jurisdicción en el Derecho Chileno. Santiago: Editorial Jurídica de Chile, pp. 61-62.

36 Artículo 11, inciso primero, del COT. "Para hacer ejecutar sus sentencias y para practicar o hacer practicar las actuaciones que decreten, podrán los tribunales requerir de las demás autoridades el auxilio de la fuerza pública que de ellas dependiere, o los otros medios de acción conducentes de que dispusieren".

37 Artículo $4^{\circ}$, inciso primero, de la Ley No 18.961, "Ley Orgánica Constitucional de Carabineros de Chile". "Carabineros de Chile prestará a las autoridades judiciales el auxilio de la fuerza pública que estas soliciten en el ejercicio de sus atribuciones”.

38 En cuanto al motivo de norma este se encuentra en el artículo 76 constitucional, la Cuarta Comisión Legislativa señaló que "esta materia, que se encuentra consultada en el artículo $3^{\circ}$ de la ley orgánica de Carabineros, encuentra su fundamento constitucional en los artículos 73 y 90 de la Carta Fundamental”. Historia De la Ley No 18.961 (1989) Oficio del "Secretario de Legislación de la Junta de Gobierno", en el que se "Informa Proyecto de Ley Orgánica Constitucional de Carabineros”, Boletín N¹.206-02, p. 81.

39 Artículo $1^{\circ}$, inciso primero, DL N 2.460 "Dicta ley orgánica de Policía de Investigaciones de Chile" "La Policía de Investigaciones de Chile es una Institución Policial de carácter profesional, técnico y científico, integrante de las Fuerzas de Orden, dependiente del Ministerio del Interior y Seguridad Pública, cuyo personal estará sometido a un régimen jerárquico y disciplinario estricto. Se vinculará administrativamente con el referido Ministerio a través de la Subsecretaría del Interior”. 
desfavorezcan a sus destinatarios, únicamente en los Estados de Excepción Constitucional, por lo que -al contrario- cabe colegir que en estado de normalidad el Jefe de Estado queda impedido de ejercer tal atribución.

Es el caso del artículo 43, inciso primero, mediante el cual el Presidente de la República, "queda facultado" en Estado de Asamblea, para "interceptar, abrir o registrar toda clase de documentos y toda clase de comunicación", y también en el inciso segundo del precitado artículo, en el cual se entrega competencias al Primer Mandatario para, en Estado de Sitio, "arrestar a las personas en sus propias moradas o en lugares que la ley determine".

c) Finalmente, confirma la interdicción de la utilización de medios coactivos para el Estado, a excepción de los tribunales de justicia, que el Constituyente no haya establecido la misma competencia para otros organismos, cuyos actos reguardan bienes jurídicos esenciales como los Intendentes y Gobernadores -artículos 111 y 112 de la Constitución- y el Ministerio Público -artículo 83 de la CPR-.

Es especialmente relevante el caso del Ministerio Público. Este organismo constitucional, tiene como fin proteger la seguridad de las personas, por los hechos que afecten su indemnidad física, síquica o patrimonial, investiga eventuales delitos y puede ejercer de la acción penal pública para su prosecución.

No obstante la relevante finalidad antes notada, el constituyente le prohibió aplicar sus actos desfavorables -artículo 83, inciso tercero de la Constitución-, y además decidió condicionarlos expresamente a la aprobación judicial previa, antes de su aplicación.

2.2.2) La Ley No 19.880 desarrolla coherentemente el mandato constitucional, al no alterar la competencia de los tribunales de justicia para aplicar sus actos desfavorables, pues descarta dispensar igual facultad a la Administración del Estado. Lo anterior se fundamenta en (a) el texto de la Ley No 19.880, (b) su lógica, (c) la historia de su establecimiento, (d) y el contraste con la norma extranjera que le dio origen.

a) La Ley No 19.880, en su artículo 30, inciso octavo, y el Capítulo III, Párrafo $3^{\circ}$, titulado "ejecutoriedad", solo reafirma que el acto administrativo es imperativo y que obliga desde que es publicado o notificado, según fuere del caso. A contrario sensu, el precepto jamás otorga la competencia genérica de aplicar los actos desfavorables a la Administración del Estado, esto se debe a que no individualiza al órgano titular de la competencia ni el contenido de la potestad ${ }^{40}$.

40 Existen aquellos que sostienen que la Ley No 19.880 , en cuanto a su tenor literal sí es suficiente para conceder una competencia residual, estos seńalan que la norma procedimental 
Las expresiones de la Ley No 19.880 que formularían una competencia genérica de autotutela ejecutiva, son: el artículo $3^{\circ}$, inciso octavo, cuando señala que los actos administrativos autorizan "su ejecución de oficio por la autoridad administrativa” y dentro del Capítulo III, Párrafo $3^{\circ}$, los artículos 50 y especialmente el 51, en la parte que menciona que los actos administrativos "causan inmediata ejecutoriedad". Se suma a lo anterior, lo invocado por el artículo $3^{\circ}$, inciso octavo, en la parte que señala "salvo que mediare una orden de suspensión dispuesta por la autoridad administrativa dentro del procedimiento impugnatorio o por el juez, conociendo por la vía jurisdiccional'.

Las competencias de los órganos administrativos, de acuerdo a lo prescrito en el artículo $7^{\circ}$ constitucional son especiales -ya que cada uno posee una órbita distinta de poderes ${ }^{41}-$, de donde se sigue que si ley crea una potestad sin determinar a su destinatario, es lo mismo que no la haya conferido $^{42}$.

En el caso de los precitados artículos, no aparece que “un 'órgano' específico, preciso" 43 pueda ejercer la atribución, por lo que malamente algún órgano podría ser competente. Así, los preceptos de la Ley $\mathrm{N}^{\circ} 19.880$ son indeterminados en cuanto a su titular, pues no puede sostenerse que identifican a un órgano destinatario de la autotutela ejecutiva.

De igual modo, las competencias son específicas - poseen un límite bien precisado ${ }^{44}$, por lo anterior su descripción al menos debe comprender un verbo rector. El artículo $3^{\circ}$ y el Capítulo III, Párrafo $3^{\circ}$, de la Ley No 19.880 señalan que la competencia consistiría en "ejecutar". Ejecutar es un verbo del que no es posible desprender que en su virtud la Administración del Estado pueda aplicar la fuerza pública, clausurar un estableci-

contiene los requisitos mínimos para ejecutar forzosamente un acto, siendo estos “(i) el Acto Administrativo como título de ejecución, (ii) no se requiere la firmeza de acto y (iii) notificación previa de su iniciación” confrontar con Villar Cárdenas, Hernán (2006) La ejecución forzosa de los actos de la Administración en el derecho chileno. memoria de título para optar al grado de licenciado en ciencias jurídicas y sociales. pp. 13 y ss. Eduardo Cordero agrega a lo anterior, que la Ley No 19.880 prescribe que el acto que ordene la coacción deberá ser "suficientemente determinado o determinable", Cordero Quincazara (sin fecha) 127-128.

41 Soto Kloss, Eduardo (2009) Derecho Administrativo: Temas Fundamentales. Santiago: Editorial LegalPublishing, p. 130.

42 Pues si existiera una atribución sin un órgano destinado expresamente a ejercerla, no podría concluirse que todos son competentes, sino que al contrario, ninguno lo es.

43 Soto KLoss (2009) 126-127. Los autores están contestes en que las competencias administrativas se entregan a órganos determinados, y a lo sumo a organismos determinados, así por ejemplo se ha dicho que "la competencia es entregada por ley al órgano administrativo y en ocasiones, directamente al funcionario dentro del órgano que debe ejercer la misma”, Bermúdez Soto, Jorge (2011) Derecho Administrativo General. Santiago: Editorial LegalPublishing, p. 321.

Soto KLoss (2009) 130. 
miento, o bien demoler una obra ${ }^{45}$. Si así lo hubiese querido el legislador lo habría dicho expresamente.

Es así que la Ley $\mathrm{N}^{\circ} 19.880$ no concede una competencia puesto que no responde a las siguientes preguntas, quién puede ejercer una competencia, ni qué competencia se puede llevar a cabo. Por esto es más apropiado entender que el sentido de la norma es asentar que los actos administrativos, una vez publicados o notificados, nacen, imperan, obligan y son exigibles.

b) La Ley No 19.880 versa sobre un procedimiento previo a la emisión de un acto administrativo, y acerca de las normas relativas a su entrada en vigencia, de tal suerte que no se refiere a competencias posteriores al momento en que impera -véase capítulo I, punto 1-. Entonces, siendo la Ley No 19.880 una de procedimiento, y no de atribuciones administrativas, solo se refiere a aquel y no a estas.

En el mismo sentido, la Ley de Procedimientos Administrativos únicamente concreta los artículos 7o, 19 No 3, inciso sexto, y 63 No 18 constitucionales, en orden a definir de modo general y supletorio las ritualidades que anteceden a la emisión de un acto $^{46}$. En lo que nos interesa, en el Capítulo III, Párrafos $1^{\circ}$ y $2^{\circ}$, se discurre acerca del modo en que se notifican y publican los actos administrativos, para luego, en el Párrafo $3^{\circ}$, referirse a su ejecutoriedad. El artículo 51, inserto en el Capítulo III, Párrafo $3^{\circ}$, define qué se entiende por tal: luego de adelantar, en el inciso primero, que los actos administrativos ocasionan inmediata ejecutoriedad, el inciso segundo prescribe que "producirán efectos jurídicos desde su notificación o publicación, según sean de contenido individual o general'.

Este contexto normativo es prístino en su sentido, ya que si bien los actos en general deben ser aplicados por la autoridad administrativa -inclusive sin el impulso procesal de un eventual requirente-, esto no implica que lo deban ser por la fuerza en caso que sean desobedecidos por sus destinatarios. La anterior idea emana de la relación entre los citados preceptos con el artículo $8^{\circ}$, inciso primero, de la Ley $\mathrm{N}^{\circ} 18.575$, el cual

45 Advierte esto Eduardo Cordero, quien señala que la inexistencia de medios "podría dejar la ejecutividad de los actos administrativos como un mero enunciado", pero para él el asunto se soluciona puesto que "existe una suerte de legislación común sobre la materia, en donde actúan las autoridades regionales y provinciales, especialmente el Gobernador, a través del auxilio de la fuerza pública para el cumplimiento de las decisiones adoptadas por la autoridad administrativa" CoRdero Quincazara (sin fecha) 129.

46 La doctrina está, unánimemente, de acuerdo en que la Ley No 19.880 es solo una ley de procedimiento véanse Soto Kloss (2009) 261, Cordero Vega, Luis (2003) El procedimiento administrativo. Santiago: Editorial LexisNexis, p. 48, Bocksang Hola, Gabriel (2006) El Procedimiento Administrativo Chileno: Estudio analítico y sistemático de coherencia. Santiago: Editorial LexisNexis, p. 3, Boloña Kelly, Germán (2005) El Acto Administrativo. Santiago: Editorial LexisNexis, p. 185. 
reafirma que, dentro del procedimiento administrativo, los órganos "actuarán por propia iniciativa en el cumplimiento de sus funciones".

En consonancia con la anterior lógica -y adelantándonos a lo que describiremos en el capítulo III-, el propio legislador no se ha fiado de la eventual competencia genérica de autotutela ejecutiva, contenida en una ley de procedimientos. Lo que la realidad legislativa indica, es que con posterioridad a la entrada en vigencia de la Ley No 19.880 -el año 2003-, cuatro leyes especiales han concedido competencias especiales de autotutela ejecutiva a determinados órganos administrativos. Esto refuerza la naturaleza meramente procedimental y no competencial de la Ley No $19.880^{47}$.

c) El origen mediato de la actual Ley de "Bases Generales de Procedimientos Administrativos" es tanto el Proyecto de Ley Boletín No 683, como también la discusión legislativa suscitada en la génesis de la actual Ley No 19.880, reflejada en el Boletín No 2594-06. Estos dos antecedentes nos hacen inferir que el legislador no estimó incorporar a la ejecución de oficio como una competencia genérica de la Administración del Estado.

El precedente legislativo mediato de la Ley No 19.880 se remonta al Proyecto de Ley Boletín No 683, titulado "Bases de los procedimientos administrativos" el cual fue presentado a discusión legislativa el año 1992. Ese proyecto sí regulaba la ejecución de oficio de los actos administrativos por la propia Administración del Estado, y creaba la autotutela ejecutiva.

En el antedicho Proyecto de Ley, el Mensaje Presidencial incluía un Título II que versaba sobre el "acto administrativo", específicamente acerca de los requisitos, nulidad y ejecución de estos, en seis latos artículos -artículos 64 a 69- ${ }^{48}$. El artículo 64 establecía que "la ejecución forzosa de los actos de la Administración que impusiere al particular alguna prestación de carácter personal o patrimonial, se efectuará por los siguientes medios (...)".

Los medios o competencias genéricas referidas en el artículo 64, eran detalladamente explicitados en los subsecuentes artículos: la ejecución

47 Los preceptos que han creado dichas atribuciones, las que estudiaremos a cabalidad en el capítulo III, son: artículo 28, inciso cuarto, Ley No 20.417, que "crea el Ministerio, el Servicio de Evaluación Ambiental y la Superintendencia del Medio Ambiente” - del año 2010-; artículo $1^{\circ} \mathrm{N}^{\circ} 30$ letra a) de la Ley No 20.434, que "modifica la Ley General de Pesca y Acuicultura en materia de acuicultura” -del año 2010-; artículo único, artículo $3^{\circ}$ terdecies de la Ley No 20.504, que "modifica el régimen jurídico del transporte público concesionado", -del año 2011-; y artículo 38 de la Ley No 20.551, que "regula el cierre de faenas e instalaciones mineras" - del año 2011-.

48 En el oficio No 2196 del año 1993, en el que "atiende solicitud de la Comisión de gobierno, descentralización y regionalización del Senado que recaba opinión de este organismo acerca del proyecto de ley sobre bases de los Procedimientos Administrativos", el Contralor General de la República, al opinar respecto de este proyecto de ley, específicamente acerca del título en referencia, señaló que "el documento en análisis se pronuncia por el sistema francés de autotutela judicial, pero con numerosos resguardos del debido proceso e intervención judicial” Contraloría General de la República (1993) p. 15. 
sobre el patrimonio -artículo 65-, la ejecución subsidiaria -artículo 66 y 68-, la multa coercitiva -artículo 67- y el auxilio de la fuerza pública -artículo 69-49.

Ahora bien, el Proyecto de Ley Boletín No 683 fue ordenado archivar por el Presidente de la República, con fecha 6 de junio de 2000, lo que evidencia la voluntad de no perseverar en el fin de facultar a la Administración del Estado con tales exorbitantes atribuciones.

Más aún, con posterioridad al archivo devino el proyecto de la actual Ley No 19.880, el cual fue presentado con menos de cuatro meses de diferencia por el mismo Primer Mandatario. La historia de la Ley No 19.880 no revela que el motivo del artículo $3^{\circ}$, inciso octavo, ni del Capítulo III, párrafo $3^{\circ}$, sea la consagración de la autotutela administrativa como regla general.

La elaboración de la Ley No 19.880 presenta la siguiente particularidad, su texto se acordó en el Congreso, luego de dos indicaciones sustitutivas tanto del Presidente de la República como la de un senador. Específicamente, el texto final del actual artículo $3^{\circ}$ inciso octavo, es fruto de una indicación del senador Zaldívar ${ }^{50}$; en tanto que el Capítulo III, párrafo $3^{\circ}$, nació de la confluencia de la indicación sustitutiva del senador Silva Cimma ${ }^{51}$, más otra indicación del senador Zaldívar ${ }^{52}$ y una final indicación del Presidente ${ }^{53}$.

$49 \quad$ Este punto fue discutido por la senadora Olga Feliú Segovia, la que criticó el proyecto por establecer tal competencia. Afirmó "hasta aquí, señor Presidente, todas las normas descritas resultan convenientes para la Administración. Sin embargo, hay otras de las que discrepo absolutamente y otras respecto de las cuales tengo serias reservas. Por ejemplo, una establece la ejecución forzosa de los actos de la Administración. Sobre el particular, pienso que la Administración no puede disponer ciertas medidas y al mismo tiempo ordenar la ejecución forzosa de ellas. Creo que se trata de una materia propia de los tribunales de justicia. Igualmente, me parece que no corresponde que la Administración solicite u ordene el auxilio de la fuerza pública para ejecutar sus propios actos" Proyecto de Ley Boletín no 683-06 (1993), Primer Trámite Constitucional en el Senado, Sesión No 15, miércoles 17 de noviembre de 1993. Disponible en: http://www.senado.cl/appsenado/index.php?mo=sesioness ala\&ac=getDocumento\&teseid $=23465 \&$ legiid $=183$

50 Historia de la Ley No 19.880 (2003) Primer Trámite Constitucional en el Senado, Segundo Informe Comisión de Gobierno, 28 de agosto de 2002, Boletín N² 2594-06, p. 173. [Fecha de visita 27 de septiembre de 2013] Disponible en: https://www.google.cl/url?sa=t\& $\mathrm{rct}=\mathrm{j} \& \mathrm{q}=\& \mathrm{esrc}=s \&$ source $=$ web \&cd $=1 \& \mathrm{xad}=\mathrm{rja} \& \mathrm{ved}=0 \mathrm{CC} 0 \mathrm{QFjAA} \& \mathrm{url}=\mathrm{http} \% 3 \mathrm{~A} \% 2 \mathrm{~F} \% 2$ Fwww.leychile.cl\%2FNavegar\%2Fscripts\%2Fobtienearchivo\%3Fid\%3Drecursoslegales\%2F 10221.3\%2F500\%2F1\%2FHL19880.pdf\&ei=XRILUuqwHPfi4AP_hYD4Cg\&usg=AFQjC NGyATpAoEQw15IogRiuBrQ5KXcLFA\&bvm=bv.53371865,d.dmg

51 Quien agregó el actual artículo 50, y 51, inciso primero, Historia de LA LEY No 19.880 (2003) Primer Trámite Constitucional en el Senado, Nuevo Primer Informe de Comisión de Gobierno, 29 de septiembre de 2001, Boletín N²594-06, p. 49.

52 De cuya autoría es el actual artículo 51, inciso segundo, Historia de La LeY No 19.880 (2003), Primer trámite constitucional en el Senado, Segundo Informe Comisión de Gobierno, 28 de agosto de 2002, Boletín N²594-06, p. 169.

53 El Presidente de la República sumó el actual artículo 53, Historia de la Ley No 19.880 (2003) Primer Trámite Constitucional en el Senado, Nuevo Primer Informe de Comisión de Gobierno, 29 de septiembre de 2001, Boletín N²594-06, p. 88. 
En todas las indicaciones, y en las discusiones suscitadas al respecto, no existe ningún antecedente por el que se pudiera deducir que se propone la facultad de aplicar de oficio, por un órgano administrativo, sus anteriores actos desfavorables. Al contrario, las opiniones y discusiones gravitaron en torno a la imperatividad del acto administrativo, y no en cuanto a la ejecución de oficio de este ${ }^{54}$.

d) Ratifica lo antedicho (d.1) que nuestra Ley No 19.880, al transcribir la Ley No 30 de 1992 espańola, no haya copiado la parte en que esta norma sí recoge la autotutela ejecutiva, que allá rige ${ }^{55}$. (d.2) Dejada de lado la autotutela ejecutiva, solo queda equiparar el diseńo normativo chileno a otros, donde la regla general es la heterotutela judicial.

d.1) La Ley No 19.880 al momento tratar sobre la ejecución del acto administrativo -en su Capítulo III, Párrafo $3^{\circ}-$, importó solo un fragmento de la parte en que la Ley No 30 de 1992 se refiere a la ejecutividad de los actos administrativos y los medios de ejecución forzosa -en su Capítulo V-. Siendo que en Chile no se copió el trozo de la ley española que sí concede la potestad de ejecución de oficio, no queda más que concluir que aquí no se incorporó la autotutela ejecutiva.

La ley española, en su exposición de motivos erige a la autotutela ejecutiva como regla general, ya que "permite articular los medios de ejecución que garanticen la eficacia de la actividad administrativa" 56 , una razón que se omitió de la Ley No 19.880 -véase capítulo II, punto 2.2.3-, pues no aparece indicio ni intento alguno de que la eficacia administrativa involucrara la concesión de una nueva atribución de autotutela.

Específicamente, entre el contenido que en la ley chilena sí fue copiado, está el situado en los artículos 50 y 51, inciso primero, preceptos que no confieren la potestad de aplicar de oficio los actos desfavorables, sino que únicamente se refieren al momento desde que los actos obligan. Entre el contenido que no fue copiado, están: las razones o fundamentos de la autotutela, la formulación de la competencia legal de aplicación de oficio de los actos desfavorables, y los medios por los que se concreta esta.

\footnotetext{
54 Las discusiones más relevantes se presentaron respecto de la retroactividad de los actos administrativos, incluida en el artículo 52, inserto en el Capítulo III, Párrafo $3^{\circ}$, de la Ley No 19.880 denominada “ejecutoriedad", Historia de la Ley No 19.880 (2003) Primer Trámite Constitucional en el Senado, Nuevo Primer Informe de Comisión de Gobierno, 29 de septiembre de 2001, Boletín N²594-06, pp. 211 y 214.

55 Así lo mencionan directamente los autores españoles Esteve Pardo, José (2011) Lecciones de Derecho Administrativo. Madrid: Editorial Marcial Pons, p. 220 y García de Enterría, Eduardo (2011) Curso de Derecho Administrativo I. 15a Edición. Navarra: Editorial Thomson Reuters, p. 811.

56 Exposición de motivos de la Ley No 30 de 1992, denominada "Régimen Jurídico de las Administraciones Públicas y del Procedimiento Administrativo Común”.
} 
La ley ibérica, además señala en su artículo 95, que los órganos administrativos "podrán proceder, previo apercibimiento, a la ejecución forzosa de los actos administrativos", este es el artículo que concede la competencia de autotutela ejecutiva ${ }^{57}$. En contraposición, en Chile no se copió este precepto ni se agregó otro similar, de tal suerte que no aparece formulada esta potestad en nuestra legislación.

También la Ley No 30, de 1992, en su artículo 96 y siguientes, especificó cómo se concreta la aplicación coercitiva de los actos desfavorables -por el "apremio sobre el patrimonio, la ejecución subsidiaria, la multa coercitiva, o la compulsión sobre las personas"-. Este contenido tampoco fue incorporado a la Ley No 19.880 .

Por último, y a mayor abundamiento, no es solo la Ley No 30 de 1992 la que configura el principio de la autotutela ejecutiva en Espańa, este proviene también de instituciones inexistentes o distintas a la chilena, como la jurisdicción contenciosa administrativa general -véase capítulo II, punto 2- los que explican el régimen de la autotutela como "un sistema unitario, como una verdadera posición jurídica" 58 .

d.2) Dejada atrás la igualación entre Chile y España, en el ámbito de la autotutela administrativa, es el sistema inglés aquel que -según cierta doctrina- sería igual al nuestro. En Inglaterra, teniendo presentes las diferencias esenciales entre el sistema jurídico europeo continental -y en consecuencia el chileno- con en el allá vigente, los actos administrativos no gozan de ejecutoriedad, sino que simplemente obligan tanto como la ley que lo faculta para actuar.

En virtud de la anterior premisa, los órganos administrativos ingleses, solo pueden aplicar actos desfavorables en caso de que una ley expresa los faculte, y si el órgano administrativo actúa sin que exista tal norma, o bien no cumple con los requisitos que ella impone, el destinatario podrá

\footnotetext{
57 En el derecho español, la autoridad administrativa "no necesita recabar respaldo judicial para imponer coactivamente dicho cumplimiento (juicio ejecutivo), sino que ella puede imponer con sus propios medios coactivos, la ejecución forzosa (art. 95 LPC)" GARCía DE Enterría (2011) 517, confrontar con Sánchez Morón, Miguel (2011) Derecho Administrativo: Parte general. 6a edición. Madrid: Editorial Tecnos, pp. 550-551. García de Enterría (2011) 518.
} 


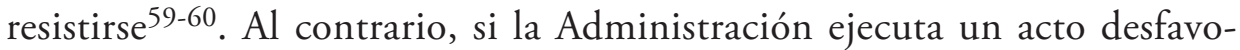
rable de acuerdo a una ley expresa, y el destinatario se resiste, solo el juez será quien puede obligarlo a cumplir el acto administrativo ${ }^{61}$.

En definitiva, las normas superiores y generales de nuestro ordenamiento jurídico, referidas al modo de aplicación de actos desfavorables, una vez que el destinatario se opone a ellos, indican que en Chile -al igual que en Inglaterra- no está formulado normativamente el principio de autotutela ejecutiva, a modo de competencia universal.

Lo que sí admiten las normas superiores chilenas, al contrario, es que los tribunales de justicia son aquellos llamados a resolver toda clase de conflictos, de consiguiente en Chile la regla general es la heterotutela judicial, en otras palabras, que frente a actos desfavorables emitidos por la Administración del Estado, son los tribunales de justicia los únicos llamados a aplicarlos. judicial?

¿Es esta regla general absoluta? ¿Existen excepciones a la heterotutela

\section{3) DE la AUTOTUTEla EJECUTIVA DE LOS ACTOS ADMINISTRATIVOS EN CHILE: UN ANÁLISIS PRÁCTICO}

Habiendo asentado ya que la Constitución y la Ley No 19.880 definen a la heterotutela judicial como la regla general, (3.1) es del caso dilucidar si esta premisa tiene excepciones (3.2) y en el evento de existir estas, huelga responder si se aplican a la realidad.

59 "El sistema anglosajón puede explicarse con cierta simplicidad, quizá porque su coherencia no precisa para nada acudir a la noción de un poder autónomo interpuesto, dotado de subjetividad y de unos especiales privilegios, poder que es la Administración en los sistema continentales (...) no cumplir lo que ordena un acto administrativo se equipara, por ello a incumplir la Ley en que el mismo se funda, lo cual constituye una infracción penal (...) pero, y aquí está lo sustancial del sistema, en ese proceso penal el inculpado podrá excepcionar sin limitaciones sobre la validez, formal y de fondo, del acto administrativo, de modo que si justifica ser un acto ilegal será absuelto y su resistencia, así legitimada" y concluye que "el que incumple un acto administrativo se arriesgará a la condena penal si el acto se demuestra legítimo, pero no incumple ninguna obligación formal de ejecutoriedad que surja del acto como tal. En otros términos el acto administrativo no es ejecutorio (...)" García de EnTERRÍA (2011) 524-528.

60 En cuanto a los actos de la autoridad en Inglaterra "cualquier ciudadano puede desconocerlos, desobedecerlos e incluso resistirlos razonable y proporcionadamente, siendo cualquier juez - y no solo el penal- el competente para pronunciarse sobre la legalidad del actuar de la Autoridad administrativa: en otros términos, el ciudadano está habilitado por el Derecho para desconocer las actuaciones irregulares del Administrador", Sото KLoss (1978) 15.

61 La Administración inglesa "deberá instar tal ejecución de los tribunales, normalmente a través del sistema de acciones penales, que, cada vez más intensas, si la desobediencia permanece, pueden concluir en la injontion (sic) promovida por el Attorney-general, cuya eficacia reside en que si la resistencia se mantiene el Tribunal puede condenar al reo a una prisión indeterminada, hasta que se muestre dispuesto a ejecutar el mandamiento del Tribunal", García de Enterría (2011) 525. 


\section{1) LA AUTOTUTEla EJECUTIVA TIENE LUGAR EN VIRTUD DE EXCEPCIONES LEGALES}

En Chile existen excepciones a la heterotutela judicial, ya que hay disposiciones normativas que así lo establecen. A partir de la precedente afirmación podemos formular una premisa: las normas superiores y generales establecen como regla en Chile la heterotutela judicial, y esta se excepciona mediante leyes especiales.

Estas leyes especiales se constituyen en anómalas contradicciones a un sistema diseñado por la Constitución y la Ley $\mathrm{N}^{\circ}$ 19.880. Si bien pensamos que estas excepciones no debiesen existir - por lo que la regla general de la heterotutela judicial siempre debiese aplicarse-, es menester reconocer la vigencia de leyes que las establecen.

La excepcionalidad de la autotutela ejecutiva es compartida por parte de la doctrina nacional. Tal como expusimos ${ }^{62}$, hay autores que predican la existencia de la regla general de la autotutela ejecutiva, empero hay otros que, a partir del análisis del ordenamiento jurídico positivo, afirman que la fórmula es la inversa: la autotutela ejecutiva es excepcional -véase a Iván Aróstica ${ }^{63}$, Juan Carlos Ferrada ${ }^{64}$, Claudio Moraga ${ }^{65}$, Rolando Pantoja ${ }^{66}$ y Eduardo Soto Kloss ${ }^{67}-$.

62 Véase Apartado 1.3).

63 En Chile la autotutela es excepcional, pues: solo se aplica para aplicar actos decisorios y desfavorables, que el destinatario no quiera cumplir por sí, y requiere una competencia previa y expresa que formule tal facultad Aróstica (1996) 78 y 79.

64 A diferencia de la ejecutividad y la ejecutoriedad "la LBPA chilena no estableció a diferencia de la espańola, que claramente le sirvió de referencia instrumentos concretos para llevar a ejecución directa sus actos, disponiendo solo su ejecutoriedad. Esto lleva a pensar que en nuestro derecho la ejecución forzosa de los actos administrativos es una potestad o privilegio entregado, por regla general, a los tribunales de justicia, salvo que la ley disponga en un caso particular esta habilitación para la Administración, señalando al mismo tiempo los instrumentos específicos para hacerla efectiva", Ferrada Borquez, Juan Carlos (2007) "Las potestades y privilegios de la administración pública en el régimen administrativo chileno”. Revista de Derecho Universidad de Valdivia, Vol. XX N 2, p. 84.

65 El autor señala, remitiéndose a lo señalado por Rolando Pantoja que "en los últimos años los tribunales de justicia y Carabineros de Chile exigen que la autoridad administrativa cuente con texto expreso de ley que faculte la exigibilidad directa del acto, para reconocer o disponer su ejecución por vía administrativa atendido a lo dispuesto por el artículo 73 (hoy art. 76) de la CPR” Moraga (2010) 103.

66 Al analizar las normas de la Ley No 18.695, específicamente las fuentes jurídicas materiales, mediante las que actúa la municipalidad, se afirma que "La LOCM no contempla la facultad de la municipalidad de recabar la fuerza pública para el cumplimiento de sus resoluciones. El DFL No 22, de 1959, de Interior, Ley de Régimen Interior, tampoco contempla la manera general del empleo de la fuerza pública para ejecutar resoluciones edilicias. De este modo, debe concluirse que la municipalidad solo puede recurrir al auxilio de la fuerza pública, con el objeto de hacer cumplir sus actos administrativos, en los casos y en la forma en que la ley expresamente haya consultado esa posibilidad (17.153/91)” Pantoja BauzÁ, Rolando (1994) Leyes administrativas sobre municipalidades. Santiago: Editorial Jurídica de Chile, p. 46.

67 El autor propone, ya en el año 1978, que la aplicación de la coacción por órganos administrativos merece "reestudiarse en una perspectiva no meramente formalista", y anticipa 
A continuación, y en consideración de los veinticinco casos excepcionales, encontrados en un estudio recopilatorio de la normativa chilena -el cual lejos de ser total, es exploratorio-, analizaremos el modo en que realmente se concibe en Chile la autotutela ejecutiva: como excepciones legales y expresas a una hipótesis asentada en la Constitución y en la Ley No 19.880 .

Definimos a la autotutela ejecutiva como las competencias legales que (3.1.1), en vista del desobedecimiento de un acto desfavorable, o en virtud a una constatación de la autoridad administrativa, permiten aplicar la fuerza pública u otra medida de coacción, sin procedimiento alguno, (3.1.2) con el fin de lograr satisfacer específicos bienes jurídicos, (3.1.3) a determinados órganos administrativos.

3.1.1) Creemos que la autotutela ejecutiva se concreta en facultades legales carentes de procedimiento por las que, un órgano administrativo, puede forzar a un particular a través de la materialización de la fuerza pública u otras vías especiales, para cumplir un acto desfavorable emitido con anterioridad, o bien a fin de someterlo a una hipótesis legal que estima infringida ${ }^{68}$.

En principio, (a) únicamente los actos desfavorables son aptos de ser ejecutados de oficio - siendo esta la causa de la autotutela ejecutiva-. (b) El modo por el cual se forzará al particular desobediente será a través de la aplicación directa de la coacción, la que siempre estará exenta de un procedimiento administrativo y judicial -siendo este el objeto de la autotutela ejecutiva-.

a) Las excepciones legales a la heterotutela judicial tienen como móvil un acto desfavorable incumplido por un particular. Consecuente con lo anterior, la explicación jurídica de la autotutela ejecutiva corresponde a la desobediencia, por parte de un destinatario de una decisión desfavorable, emitida con anterioridad, contenida en un decreto o en una resolución -véase capítulo II, punto 1-.

Calzan con tal afirmación las atribuciones entregadas a los órganos superiores de los servicios públicos, como aquella otorgada al Superintendente de Servicios Sanitarios quien puede "requerir el auxilio de la fuerza pública para el cumplimiento de sus resoluciones" -artículo 19 de la Ley No

que "seguramente, las soluciones a que se llegará con tal tratamiento no distarán mucho de sostener como principio no la autotutela ejecutiva de la Administración sino la plena heterotutela judicial", Soto KLoss (1978) 31.

68 De distinto modo, Lautaro Ríos concibe la autotutela "como un conjunto de técnicas y mecanismos destinados a fortalecer y a hacer respetable la legalidad” Ríos Álvarez, Lautaro (1985) El urbanismo y los principios fundamentales del derecho urbanistico. Tesis doctoral presentada por el autor en la Universidad Complutense de Madrid, p. 536. 
18.902, que "Crea la Superintendencia de Servicios Sanitarios"-. Siguiendo esta estructura, encontramos cinco normas que establecen la coacción para aplicar decisiones no acatadas ${ }^{69}$.

Empero, y distante de esta lógica, la legislación chilena se abstrae de este razonamiento, cuando confiere a la Administración el vigor de la coacción sin que exista un acto jurídico anterior. En los anteriores casos bastará la simple constatación del incumplimiento de una hipótesis legal, por un órgano administrativo, para aplicar la fuerza. Comúnmente estas atribuciones se relacionan con la oposición al cumplimiento de sus potestades fiscalizadoras.

Muestra de ello es que los Inspectores del Trabajo, en razón de sus facultades fiscalizadoras, pueden "visitar los lugares de trabajo" del empleador, siendo plausible que los primeros fuercen al segundo en virtud de su resistencia a someterse a tal potestad -artículo 24 y 26 del Decreto con Fuerza de Ley No 2, de 1967, del Ministerio de Trabajo y Previsión Social-. De forma análoga, encontramos dieciocho normas especiales que permiten forzar a un particular, en virtud al mero incumplimiento de una hipótesis legal ${ }^{70}$.

En la eventualidad que el ejercicio de la autotutela ejecutiva responda a una competencia fiscalizadora resistida por un particular, y mediante cuyo ejercicio se pueda afectar algún derecho constitucional de sus destinatarios, ¿podemos efectuar algún reparo en cuanto a su juridicidad?

Creemos que sí. La Constitución dispuso, en el contexto en que un fiscal del Ministerio Público pretenda aplicar la fuerza ante la oposición a sus órdenes, una solución completamente opuesta de la resuelta por leyes especiales analizadas: requerirán de "autorización judicial previa". Conteste con este parecer, el Tribunal Constitucional extendió esta hipótesis a la Administración del Estado.

En virtud del artículo 83, inciso tercero de la CPR, los fiscales del Ministerio Público solo pueden ejecutar competencias investigativas que

69 Los casos son aquellos del artículo 2 letra c) de la Ley No 19.175 y artículo 34 del DFL No 22, 1959; artículo $3^{\circ} N^{\circ} 22$, de la Ley No 18.410, que "crea la Superintendencia de Electricidad y Combustibles”; artículo $3^{\circ}$ terdecies, de la Ley No 20.504; artículo 55, del DFL No 323, de 1931 "Ley de Servicios de Gas"; y artículo 138 del CA.

70 Así por ejemplo, existe la potestad de coaccionar a un particular cuando "exista oposición a la fiscalización” -artículo 28, inciso cuarto, Ley No 20.417-. Se repite tal disposición en el: artículo 38 de la Ley No 20.551, artículo 28 de la Ley No 18.302; artículo 21, inciso cuarto, de la Ley No 18.362; artículos 5 y 13 de la Ley No 18.755; artículo 20, inciso segundo, de la Ley No 18.168; artículo 26, inciso final, $\mathrm{DL} \mathrm{N}^{\circ} 3.538$, de 1980 ; artículo $1^{\circ} \mathrm{N}^{\circ} 30$ letra a) de la Ley No 20.434; artículo 60, inciso séptimo, del CT; artículos 33 y 83, inciso segundo, del DFL N 850; artículo 4 letra d) y h) de la Ley $\mathrm{N}^{\circ} 19.175$; en el artículo $8^{\circ}$ de la Ley 10.336; artículo 155 del CS; artículo 2º, letra e) del Decreto Supremo No 1.086 de 1983. Otros casos que siguen la misma razón, pero no en cuanto a aplicar la autotutela en virtud de la oposición a la fiscalización, son: artículo 115 de la Ley No 18.700; artículo 178 del CS; y finalmente, artículo 156 del DFL No 458; y artículo 161 del DFL No 458. 
potencialmente contraríen derechos fundamentales, previa solicitud y aprobación de un juez. Esta disposición está completamente ausente en los casos que se le entrega la competencia de la coacción a un órgano fiscalizador o inspector ${ }^{71}$.

El Tribunal Constitucional extendió a la denominada "autorización judicial previa" al actuar de otros órganos que realizan similar labor, los fiscalizadores o inspectores. En la sentencia rol No $1.894^{72}$, esa Magistratura declaró la inconstitucionalidad de un precepto que habilitaba a Carabineros y a los inspectores municipales a fiscalizar, pues "el proyecto no exige esa autorización judicial previa u otro resguardo" -considerando séptimo- ${ }^{73}$.

En consecuencia, en los casos que se incumpla una hipótesis legal, cuando exista oposición al ejercicio de potestades fiscalizadoras por el órgano administrativo y sea posible lesionar derechos constitucionales, solo podría forzar al particular si la Administración se ciñese a una "autorización judicial previa”. Pero según observaremos, la autotutela ejecutiva como excepción está lejos de someterse a tal condición.

b) En las normas especiales chilenas, (b.1) el objeto de la autotutela ejecutiva se traduce en la facultad de un órgano administrativo, para ordenar directa e inmediatamente a la fuerza pública que coaccione a un particular, y excepcionalísimamente para ordenar que se realicen otras medidas. (b.2) Lo anterior no puede confundirse con otras figuras, que si bien comparten ciertos elementos de la "ejecución de oficio", no son una manifestación de tal excepción.

b.1) El propósito de la autotutela, tal como lo define la palabra, es aplicar una determinación unilateral de un órgano administrativo a la realidad. Las vías para lograr ese propósito son tanto la orden de aplicación de la fuerza pública, como otros medios particulares, en estos casos siempre se excluirá todo procedimiento.

La Administración del Estado, podrá solicitar el auxilio de la fuerza pública para la ejecución de determinados actos. A modo de ejemplo el

71 Norma que ha sido desarrollada coherentemente por el CPP, en el Libro Segundo, Título I, Párrafo $3^{\circ}$, denominado "actuaciones de la investigación", que especifica cuáles diligencias pueden ser desplegadas por los órganos inspectores, sometiendo su ejercicio en cada caso específico a la voluntad del investigado, o a la aquiescencia previa del Juez de Garantía.

72 Tribunal Constitucional. 12 de julio de 2011. Rol N i 894. "Control de constitucionalidad del proyecto de ley que sanciona el acoso sexual de menores, la pornografía infantil y la posesión de material pornográfico infantil”. Disponible en: http://www.tribunalconstitucional.cl/wp/ver.php?id=2011. [Fecha de visita 13 de septiembre de 2013] p.18.

73 A efecto de profundizar en la "autorización judicial previa”, como una nueva garantía del debido proceso constitucional, se sugiere Enteiche Rosales, Nicolás (2012) "Autorización judicial previa e impugnación supuesta de la actuación administrativa: nuevos elementos del debido proceso en la jurisprudencia del tribunal constitucional". Revista Ius et Praxis Universidad de Talca. Año $18 \mathrm{~N}^{\circ} 1$, pp. 432-438. 
Director General de Aguas tiene la facultad de "requerir al Intendente o Gobernador respectivo el auxilio de la fuerza pública" -artículo 138 del CA-. Esta modalidad de aplicación de la coacción tiene lugar en la mayoría de las leyes especiales, puesto que aparece en veinte de las veinticinco hipótesis estudiadas ${ }^{74}$.

Los casos expuestos encuentran su correlato en la Ley Orgánica Constitucional de Carabineros de Chile y en la Ley Orgánica de la Policía de Investigaciones, estas normas señalan que esos servicios prestarán "a las autoridades administrativas" el auxilio "que éstas soliciten en el ejercicio legítimo de sus atribuciones" -artículo $4^{\circ}$, inciso cuarto y artículo $7^{\circ}$, inciso tercero, respectivamente-.

Separada de la fuerza pública como objeto de la autotutela ejecutiva, existen otras señeras manifestaciones de la coacción, como lo son la decisión de demoler o clausurar un inmueble, y aquella de aplicar una medida sanitaria para el particular. Así por ejemplo, los alcaldes, pueden decretar la demolición parcial o total de una obra, o la clausura de un establecimiento o local, comercial o industrial -artículo 156 y 161 del Decreto con Fuerza de Ley No 458, de 1976, Ley de Urbanismo y Construcciones-.

Otro tanto ocurre con la atribución de los Secretarios Regionales Ministeriales de Salud -en adelante "SEREMI de Salud"-75, quienes pueden ordenar la "clausura, prohibición de funcionamiento de casas locales o establecimientos, paralización de faenas, decomiso, destrucción y desnaturalización de productos" -artículo 178 del CS-, como también las Fuerzas de Armadas y de Orden, que pueden aplicar la medida de clausura -artículo 115, de la Ley No 18.700, que crea la "Ley Orgánica Constitucional sobre Votaciones Populares y Escrutinios"-.

74 La potestad de coacción, mediante la orden directa de la aplicación de la fuerza, aparece en diversas normas: artículo $8^{\circ}$ de la Ley No 10.336; artículo 2 letras c) de la Ley $N^{\circ} 19.175$ y artículo $34^{\circ}$ del DFL № 22, de 1959; artículo $3 \mathrm{~N}^{\circ} 22$ de la Ley № 18.410; artículo 38 de la Ley No 20.551; artículo 28 de la Ley No 18.302; artículo $21^{\circ}$, inciso cuarto, de la Ley No 18.362 ; artículos $5^{\circ}$ y 13 de la Ley No 18.755 ; artículo 20, inciso segundo, de la Ley No 18.168; artículo $26^{\circ}$ del DFL $\mathrm{N}^{\circ}$ 2, de 1967; artículo 26, inciso final, del $\mathrm{DL} \mathrm{N}^{\circ} 3.538$, de 1980; artículo 28, inciso cuarto, de la Ley $\mathrm{N}^{\circ} 20.417$; artículo $1^{\circ} \mathrm{N}^{\circ} 30$ letra a) de la Ley No 20.434; artículo 60, inciso séptimo, del CT; artículos 33 y 83, inciso segundo, del DFL 850, de 1997; artículo $19^{\circ}$ de la Ley No 18.902 ; artículo $3^{\circ}$ terdecies de la Ley No 20.504; artículo $55^{\circ}$ del DFL $N^{\circ} 323$, de 1931; y artículo 20, letra e) del Decreto Supremo No 1.086, de 1983; artículo 4 letra d) y h) de la Ley No 19.175; y artículo 155 del CS.

75 La competencia del SEREMI de Salud para aplicar este artículo -como también el artículo 178 del CS- arranca del propio CS, en relación con el artículo 4, $\mathrm{N}^{\circ} 3$, del Decreto con Fuerza de Ley $\mathrm{N}^{\circ}$ 1, de 2006, del Ministerio de Salud que "Fija texto refundido, coordinado y sistematizado del Decreto Ley $\mathrm{N}^{\circ} 2.763$, de 1979 y de las Leyes $\mathrm{N}^{\circ} 18.933$ y $\mathrm{N}^{\circ} 18.469$ ”. No obstante, en las diversas materias, otros organismos contemplados en el citado DFL podrían poner en práctica dichas atribuciones, así a modo de ejemplo corresponderá a los Servicios de Salud respectivos, en virtud del artículo 23 del Decreto Supremo No 133, de 1984, del Ministerio de Salud, aplicar estas medidas. Para efectos prácticos, cuando nos refiramos a la aplicación de la autotutela ejecutiva, solo individualizaremos a los SEREMI de Salud. 
Independiente de la vía por la que se manifieste la autotutela, es un elemento de la esencia en nuestro ordenamiento jurídico que las leyes especiales excluyan al órgano administrativo de un procedimiento administrativo, y de uno judicial ${ }^{76}$.

La ejecución de oficio acarrea como un requisito de la esencia la instantaneidad entre la amenaza cernida, y el acaecimiento de una respuesta para evitar su concreción ${ }^{77}$. En otras palabras, la coacción emergerá de la aplicación de una disposición legal por una de las partes -la Administración-, sin que la otra -el afectado- pueda conocer los cargos que se le formulan ante la propia Administración, ni frente a un juez.

Así, un precepto legal solo puede clasificarse como en uno que confiere la autotutela ejecutiva, en caso que se dote a la Administración de la fuerza pública o de otra vía análoga, que goce de inmunidad procedimental. Lo anterior tendrá lugar siempre que se entregue la antedicha potestad y no se describa un procedimiento que prepare su emisión, ni aparezca que hay una vía expresa para su posterior impugnación.

En esta lógica caen todos los casos en que se confiere la fuerza pública a un organismo administrativo, pues las normas que entregan la facultad no prevén ritualidades previas a la orden impartida a los servicios competentes, ni confieren algún recurso judicial expreso contra el ejercicio de esta ${ }^{78}$.

76 Tanto es así que en un voto disidente de dos Ministros del Tribunal Constitucional, se calificó que la ablación de la jurisdicción que implica consagrar la "autotutela ejecutiva”, era merecedora de una norma de carácter orgánica constitucional, toda vez que está privando de atribuciones al Poder Judicial. La disidencia seńaló “(...) el artículo $3^{\circ}$ terdecies incorporado a la Ley $\mathrm{N}^{\circ} 18.696$ por el numeral 4) del artículo único del proyecto de ley, en la parte que faculta al Ministerio de Transportes y Telecomunicaciones para aplicar la fuerza pública en caso de incumplimiento de sus órdenes, instrucciones y resoluciones, por estimar que contiene una norma propia de ley orgánica constitucional, comoquiera que esta autotutela ejecutiva le permite hacerse justicia por propia mano, directamente y con prescindencia de los tribunales a que se refiere el artículo 76 de la Constitución". Tribunal ConstitucioNAL. 15 de marzo de 2011. Rol $\mathrm{N}^{\circ}$ 1912. Disidencia a sentencia rol $N^{\circ} 1912$. "Control de constitucionalidad del proyecto de ley aprobado por el Congreso Nacional que modifica el régimen jurídico del transporte público concesionado". Disponible en: http://www.tribunalconstitucional.cl/wp/ver.php?id=1799. [Fecha de visita 13 de septiembre de 2013] p.7.

77 Así por ejemplo, en el Derecho Civil, al instante en que las raíces penetren en suelo ajeno, el dueño tiene derecho a cortarlas (artículo 942 del CC), en el Derecho Laboral se otorga la facultad a los trabajadores para declararse en huelga (artículo 369 y siguientes del CTra), y a la sazón, el empleador podrá una vez que se declare esta, impedir temporalmente el acceso a todos los trabajadores a la empresa (artículo 375 del CTra); y en el Derecho Penal se contempla la legítima defensa, o bien el estado de necesidad (artículo 10, número cuarto, quinto, sexto y séptimo del CP).

78 Estimamos que la existencia de acciones constitucionales -tales como el Recurso de Protección o el de Amparo- no satisface la exigencia de un debido procedimiento judicial, sino que configuran una base mínima en vista del respeto al principio de impugnación de los actos administrativos. En otras palabras, existirá debido proceso, y en consecuencia dejaremos de estar en presencia de la autotutela ejecutiva, cuando el afectado por ella pueda interponer 
De igual modo en los casos especiales en que se faculta a demoler, clausurar y en aquel que permite aplicar medidas sanitarias, la fuerza se materializa "sin más trámite" o por la contravención de "las disposiciones de la presente ley" -artículo 156 y 161 del Decreto con Fuerza de Ley No 458-, y "con el solo mérito del acta" -artículo 178 del CS-, respectivamente. Además, el legislador situó expresamente estas atribuciones fuera de otras normas, en las que sí se contemplan procedimientos administrativos y judiciales.

b.2) Ahora bien, existen situaciones excepcionalísimas que comparten aspectos comunes con la "ejecución de oficio" pero que no contienen uno o más aspectos que determinan su existencia. Estas son, (i) las sanciones administrativas, (ii) el procedimiento de cobro de multas administrativas, y el (iii) "solve et repete".

(i) Las sanciones administrativas no poseen la misma causa, ni idéntico objeto a las competencias de autotutela ejecutiva, puesto que aquellas contemplan un procedimiento administrativo y judicial anterior a su ejecución, que estas omiten. Lo anterior se explica porque toda sanción administrativa se aplica con garantías procesales y sustantivas, que condicionan la concreción de la decisión de castigar.

Las sanciones administrativas, tal como lo ha decidido el Tribunal Constitucional, obligan al legislador a establecer un debido proceso previo a su aplicación. Esto implica que la ley donde se concede una competencia, de modo expreso debe fijar un procedimiento ante el órgano que la aplica ${ }^{79}$, y uno posterior ante el juez que controla su ejecución ${ }^{80}$.

El modo en que se constituye el debido proceso administrativo es mediante la existencia de formulación de cargos y la posibilidad del parti-

una acción judicial expresa -establecida por una ley- en contra del acto que ordene la aplicación de la coacción.

79 El Tribunal Constitucional señaló, con precisión, que la existencia de un recurso jurisdiccional no sanea o convalida la inexistencia de un procedimiento administrativo, se expresó en la sentencia que "el derecho a la defensa jurídica debe poder ejercerse, en plenitud, en todos y cada uno de los estadios en que se desarrolla el procedimiento, en los cuales se podrán ir consolidando situaciones jurídicas muchas veces irreversibles. No es, en consecuencia, suficiente permitir accionar ante el Tribunal Calificador de Elecciones para entender que, por esa sola circunstancia, se ha convalidado una actuación administrativa constitucionalmente objetable" Tribunal Constitucional. 16 de junio de 2003. Rol No 376, considerando trigésimo séptimo. "Control de constitucionalidad respecto del proyecto de ley sobre transparencia, límite y control del gasto electoral". Disponible en: http://www.tribunalconstitucional.cl/wp/ver.php?id=244 [Fecha de visita 13 de septiembre de 2013]

80 El procedimiento judicial es, de igual modo a que el procedimiento administrativo, un elemento de la esencia en las sanciones administrativas, de tal forma que aquellas que carezcan de este no pueden "considerarse ajustadas a la Constitución" Tribunal Constitucional. 21 de octubre de 2010. Rol No 1518, considerando decimoctavo "Requerimiento de inaplicabilidad por inconstitucionalidad de María Angélica Sánchez Vogel y otros, respecto del artículo 169 del Código Sanitario". Disponible en: http://www.tribunalconstitucional. cl/wp/ver.php?id=1587. [Fecha de visita 13 de septiembre de 2013] 
cular de defenderse de ellos, ante el órgano sancionador. La forma en que tiene lugar el debido proceso jurisdiccional es a través de la presencia de una acción jurisdiccional, en cuya virtud se pone en conocimiento de una reclamación a un tercero independiente e imparcial, quien decide si su aplicación es o no jurídica.

Existen casos especiales, en los que al crearse una sanción administrativa no habrá un procedimiento administrativo establecido en la misma ley, pero sí un recurso judicial especial en contra de la decisión adoptada. A estos casos los calificamos como sanciones administrativas imperfectas, ya que si bien no respetan el debido proceso, contemplan la sumisión ante un tribunal de justicia previo a su aplicación, desvirtuándose el carácter de autotutela.

Como ejemplo aparece la medida de "expulsión de extranjeros", que poseen tanto del Ministerio del Interior como los Intendentes y Gobernadores -artículo 84, Decreto Ley No 1.094, de 1975-, misma suerte sigue la "clausura del establecimiento o faena" que pueden aplicar los Inspectores del Trabajo -artículo 34 y 35 del Decreto con Fuerza de Ley No 2, de 1967-.

(ii) El cobro de multas administrativas tampoco constituye una excepción a la heterotutela judicial ${ }^{81}$, ya que el funcionario administrativo que ejecuta la recolección lo hace en la calidad ficta de juez, y la orden de cobro sobre los bienes del particular siempre puede ser controvertida en sede judicial, frente a un juez ordinario.

Una vez que un órgano de la Administración del Estado emite una multa, si el afectado no reclama de esta o si el reclamo es rechazado, se iniciará el procedimiento de cobro. Las multas administrativas se recaudan de acuerdo a lo prescrito por el Libro III, Título V del CT, esto tiene lugar debido a una remisión del artículo $2^{\circ}$, No 2 , letra b) ${ }^{82}$, Decreto con Fuerza de Ley No 1, del Ministerio de Hacienda, de 1994, "Estatuto Orgánico del Servicio de Tesorería”, y del artículo $35^{83}$ del Decreto Ley No 1.263, sobre Administración Financiera del Estado.

81 En contra, Hernán Villar señala que, a causa del artículo $2^{\circ}$ № 1 (sic), se configura "la ejecución forzosa administrativa por medio de una (sic) apremio sobre el patrimonio del deudor" VILLAR (2006) 19.

82 Artículo $2^{\circ}$, No 2, letra b) del DFL No 1, del Ministerio de Hacienda, de 1994, que "fija el texto refundido, coordinado, sistematizado y actualizado del estatuto orgánico del Servicio de Tesorerías" "El Servicio de Tesorerías tendrá las siguientes funciones: (...) 2.- Efectuar la cobranza coactiva sea judicial, extrajudicial o administrativa de: (...) b.- Las multas aplicadas por autoridades administrativas".

83 Artículo 35 del DL No 1.263, de 1975, que establece "El Servicio de Tesorerías tendrá a su cargo la cobranza judicial o administrativa con sus respectivos reajustes, intereses y sanciones de los impuestos, patentes, multas y créditos del Sector Público, salvo aquellos que constituyan ingresos propios de los respectivos Servicios. Para tal efecto, aplicará, cualquiera que sea la naturaleza del crédito, los procedimientos administrativos y judiciales establecidos por el CT para el cobro de los impuestos morosos". 
El anterior procedimiento, denominado "del cobro ejecutivo de las obligaciones tributarias de dinero" consta de dos partes, una tramitada frente a un juez especial, constituido por el Tesorero Regional o Provincial del Servicio de Tesorerías ${ }^{84-85}$-artículo 168 a 175, del CT-, y otra que surge a partir de la "oposición del ejecutado", sustanciada ante un Juez de Letras de Mayor Cuantía -artículo 176 a 189, del CT_86.

De la preceptiva recién resumida podemos concluir que no existe la autotutela ejecutiva para cobrar multas administrativas. Esto se debe a que las propias leyes especiales desligan al órgano administrativo competente de su carácter de tal, y le atribuyen la calidad de juez sustanciador. Así, el procedimiento de cobro es judicial, y no administrativo -artículo $2^{\circ}$, No 6, 13 letra e), 22 del Decreto con Fuerza de Ley No 1, del Ministerio de Hacienda, de 1994, y artículo 170, inciso primero del CT-.

De igual forma, si atendemos a que el procedimiento frente al Juez de Letras principia con la oposición del particular ejecutado -artículo

84 Esto pues, el artículo 22 y siguientes del DFL de Ley No 1, del Ministerio de Hacienda, de 1994, que "fija el texto refundido, coordinado, sistematizado y actualizado del estatuto orgánico del Servicio de Tesorerías" señala que la calidad de juez no la tendrá el Tesorero Comunal, tal como aparece en el Libro III, Título V, del CT, sino que el Tesorero Regional o Provincial, según sea del caso.

85 Circunstancia que es diversa a la del Director Regional del Servicio de Impuestos Internos, quien no tuvo ni tiene la calidad de juez, véase nuestro artículo al respecto Enteiche RosaLES, Nicolás (2012) "Ley N²0.322: Avances y desafíos respecto de la inspección y sanción de infracciones administrativas en materia tributaria". Revista Actualidad Jurídica. Año 2012 $\mathrm{N}^{\circ} 26$, pp. 266-269.

86 Así lo han establecido los tribunales superiores de justicia al analizar el artículo 170 del CT, se ha dicho que "de la disposición antes transcrita fluye claramente la conclusión de que no existen dos procedimientos de naturaleza diferente, uno administrativo y otro judicial, sino que se trata de un solo procedimiento ejecutivo que en una primera fase se radica en un juez especial: el Tesorero Comunal (hoy Tesorero Regional o Provincial en virtud del artículo $4^{\circ}$, del DFL No 178,de 1981, del Ministerio de Hacienda, que "fija norma de reorganización y del personal del servicio de tesorerías") quien no actúa como funcionario administrativo propiamente tal, sino en el carácter de juez sustanciador y la providencia mediante la cual despacha el mandamiento de ejecución y embargo no abre un expediente administrativo sino que hará de auto cabeza de proceso". Corte de Apelaciones de Punta Arenas. 7 de agosto de 2007. Rou No 164-2007. "Tesorería regional de Magallanes con deudores morosos". Disponible en: http://corte.poderjudicial.cl/SITCORTEPORWEB/. [Fecha de visita 13 de septiembre de 2013] considerando quinto; y Corte de Apelaciones de Santiago. 7 de julio de 1999. Rol No 485-1998. "Tesorería Regional Metropolitana con Iván Patricio Sánchez Santibánez”. Gaceta Jurídica 229, Año 1999, considerando octavo. De esta manera, el procedimiento administrativo de cobro, no es tal, sino que, de igual forma a lo resuelto mediante otra sentencia "(...) tanto expediente llamado administrativo como la tramitación ante el juez civil constituyen un todo homogéneo y no son dos distintos de naturaleza diferente. Es un solo procedimiento, el que se tramita en una primera fase ante un juez especial, el que tiene el carácter de sustanciador según lo señala el artículo 170 del CT, y una segunda seguida ante el juez ordinario (...)" Corte de Apelaciones de Temuco. 21 de enero de 2010. Rol No 1864-2009, considerando séptimo. "Fisco de Chile con Pereira Jiménez Juana". Disponible en: http://corte.poderjudicial.cl/SITCORTEPORWEB/. [Fecha de visita 13 de septiembre de 2013] 
180, del CT-, podemos inferir que el particular siempre podrá oponerse frente a un tribunal integrante del Poder Judicial.

(iii) De igual modo, el solve et repete, o la obligación legal de depositar una parte o el total de una multa emitida por un órgano administrativo, antes de poder reclamar de ella ante un tribunal de justicia, no es una manifestación de la autotutela administrativa. El descrito entramado se constituye únicamente como una regla de carácter procedimental, que condiciona el reclamo a la consignación de una cantidad de dinero ${ }^{87}$.

En virtud de esta figura, algunas leyes especiales ${ }^{88}$ obligan al particular a que deposite una cantidad de dinero, para que pueda ser conocido su reclamo por la justicia. Pues bien, en este caso no existe un acto administrativo que coaccione al particular para que este cumpla uno anterior, por el contrario son las leyes especiales y un acto judicial los que imponen la obligación legal de depositar todo o parte de esta, antes de poder reclamarla.

De otro modo, no existe un acto de la Administración que compela a cumplir uno anterior, sino que es la propia ley la que condiciona el reclamo judicial a un depósito. Cabe notar que las leyes que incorporan esta gabela han sido progresivamente rebajadas, tanto en su número como en la cantidad de dinero que se exige antes del reclamo frente al juez ${ }^{89}$.

Entonces el solve et repete tiene por objeto disuadir la interposición de reclamaciones judiciales, ya que exige al afectado por un acto desfavorable poseer y consignar una cantidad de dinero, y no versa acerca de la ejecución de un acto administrativo previamente emitido ${ }^{90}$.

87 En contra, Patricio Aylwin señala que "es el principio que, en materia financiera se expresa con los términos "solve et repete". Así, el condenado a una multa, puede reclamar, pero debe pagarla. Si se acoge su reclamación, se le devolverá lo pagado” Aylwin (1952) 160; del mismo modo Mónica Madariaga afirma que de la ejecutoriedad "deriva el principio del 'solve et repete', en cuya virtud, para impugnar un acto es condición previa su cumplimiento integral”, MADARIAGA (1965) 61.

88 Las leyes especiales que consagran esta limitación al derecho de acceso a la justicia, son cada vez menos, entre las que aún subsisten están aquellas del: artículo 22 de la Ley No 18.707, que "Introduce modificaciones a legislación bancaria"; artículo 30 del DL No 3.538; artículo 19 de la Ley No 18.410; Artículo 58, de la Ley No 16.395 que "Fija el texto refundido de la Ley de organización y atribuciones de la Superintendencia de Seguridad Social"; artículo 94 No 8, del DL No 3.500 que "Establece nuevo sistema de pensiones"; artículo 7o, de la Ley No 18.933 que "Crea la Superintendencia de Instituciones de Salud Previsional, dicta normas para el otorgamiento de prestaciones por Isapre y deroga el DFL N³ 3, de Salud, de 1981”. Así se evidencia en la sentencia rol No 1580 del Tribunal Constitucional, la que ilustra cómo el legislador y la propia magistratura constitucional progresivamente han derogado e inaplicado, respectivamente, al "solve et repete", Tribunal Constitucional. 26 de enero de 2011. Rol No 1580, considerando tercero, cuarto y séptimo. "Requerimiento de inaplicabilidad por inconstitucionalidad presentado por Farmacias Cruz Verde S.A. respecto del inciso tercero del artículo 474 del Código del Trabajo". Disponible en: http://www.tribunalconstitucional.cl/wp/ver.php?id=1759. [Fecha de visita 13 de septiembre de 2013]

90 Esta figura procedimental es en sí inconstitucional, tal como lo declaró el Tribunal ConsTITUCIONAL. ROL N ${ }^{\circ} 1580$, considerando octavo. 
3.1.2) Que todo organismo administrativo deba propender al bien común, y que los órganos que lo componen actúen guiados en virtud del resguardo de las personas, no es una primicia -artículo $1^{\circ}$, inciso cuarto, de la CPR-. Tampoco es original asentar que el ejercicio de toda competencia tiene que atender a un bien jurídico, basándose en comprobables motivos de hecho y de derecho.

Más allá de lo antedicho, (a) es lo cierto que al formularse una competencia excepcional, como lo es la autotutela ejecutiva, el legislador debiera prever que el objetivo de su ejercicio no será exclusivamente la satisfacción de cualquier bien jurídico, sino de uno calificado. (b) A la sazón, el órgano administrativo tendrá que justificar especialmente por qué pone en práctica algo extraordinario.

a) El legislador, cuando contempla la autotutela, en cuya virtud se omite expresamente todo procedimiento, fundamenta esta anomalía en trascendentes objetivos. Por otra parte, existen ciertas competencias que no evidencian propender inmediata y directamente a un bien jurídico relevante.

Podemos clasificar la especial finalidad del ejercicio de la coacción administrativa dependiendo del órgano y contexto en que esta se confiere. Resultando que el objetivo de la autotutela, de acuerdo al anunciado encasillamiento, consiste en la protección a: (a.1) la vida e integridad física y síquica, (a.2) el orden público, (a.3) y otros difusos.

a.1) La vida e integridad física y síquica se tutelan a través de las medidas extraordinarias que se otorgan al SEREMI de Salud respecto de la prevención y/o represión de riesgos sanitarios; como también mediante la facultad de demolición conferida al alcalde, a fin de evitar la caída de construcciones que, inminentemente, amenazan ruina.

Así, el CS permite al SEREMI de Salud "en casos justificados" aplicar diversas medidas sanitarias, y en caso de que sean otros funcionarios quienes dispongan estas, deberán hacerlo siempre que "exista un riesgo inminente para la salud" -artículo 178 del CS-. De igual forma, el Decreto con Fuerza de Ley No 458, faculta al alcalde para ordenar la demolición "cuando el peligro de derrumbe sea inminente" -artículo 156-.

a.2) Con miras a restablecer el orden público, Carabineros de Chile como las Fuerzas Armadas y de Orden, en su caso, pueden aplicar la fuerza a fin de asegurar el correcto ejercicio del Derecho de Reunión y a Sufragio. De igual modo es posible coaccionar directamente a un particular por el Gobernador a fin de que se desocupe un bien público.

En virtud de lo anterior Carabineros de Chile, gracias al Decreto Supremo No 1.086 del Ministerio del Interior, de 1983, puede sin intermedio de una orden previa de otro órgano administrativo coaccionar a los particulares. El objeto de dicha norma es restablecer el orden público en caso que se infrinja la regulación ahí contenida -artículo $2^{\circ}$, letra e)-. 
También, en razón de la Ley No 18.700, las Fuerzas Armadas y de Orden tienen la atribución de clausurar locales en que se "realicen actividades de propaganda o se desarrollen reuniones de carácter electoral" o bien en caso que se realicen espectáculos masivos, dentro del período de tiempo que ahí se señala -artículo 115 y 116-.

Por último, la Ley No 19.175 "Orgánica Constitucional sobre Gobierno y Administración Regional", señala que en caso de ocupaciones ilegales de bienes nacionales de uso público, el Gobernador "exigirá administrativamente su restitución" -artículo 4 letra d) y h)-.

a.3) Finalmente hay casos en que ciertas leyes permiten coaccionar sin que exista un bien jurídico específico que se resguarde. En este sentido resultan paradigmáticas las atribuciones tanto del alcalde para clausurar establecimientos, en el evento que se "contravinieren las disposiciones de la presente ley, de la Ordenanza General y de las Ordenanzas Locales" -artículo 161 del Decreto con Fuerza de Ley No 458-, como la del intendente a fin de requerir el auxilio de la fuerza pública "en conformidad a la ley" -artículo $2^{\circ}$, letra c), Ley 19.175-91.

La omisión en la consagración legislativa de un bien jurídico específico que justifique la potestad de ejecución de oficio, también se expresa en normas que conceden la autotutela para que se apliquen todas las resoluciones de un organismo, o bien a fin de que se puedan ejercer sus competencias fiscalizadoras.

Las hipótesis jurídicas antes descritas poseen un aspecto en común: justifican la coacción únicamente en la relevante finalidad del organismo en el que se sitúa tal atribución, sin ahondar ni poner en relieve el objetivo que ha de perseguir el órgano que la puede aplicar.

91 En la evolución legislativa del actual texto de la Ley No 19.175, al momento de discutirse el citado artículo, el autor de la indicación por la cual se sustituyó la palabra "disponer" por "requerir" del auxilio de la fuerza pública, el senador Huerta, señaló "que, en su opinión, la norma propuesta en el texto en debate envuelve la idea de dependencia de Carabineros e Investigaciones al intendente, pues la forma verbal "disponer" supone "mandarlo que ha de hacerse", y ello se opone al artículo $4^{\circ}$ de la Ley Orgánica Constitucional de Carabineros, que señala que Carabineros "prestará, a las autoridades administrativas el auxilio de la fuerza pública que estas le soliciten. Por lo expuesto, sugiere emplear la expresión "requerir” que implica un imperativo de autoridad u orden perentoria de la cual el órgano requerido no se puede sustraer de cumplir ni de condicionar su cumplimiento, al tiempo que evita transformar a la autoridad administrativa en el superior directo de Carabineros con infracción del marco constitucional que señala una dependencia distinta para las Fuerzas de Orden”. Por la unanimidad de sus miembros presentes, las Comisiones unidas prestaron su aprobación a la indicación formulada” Historia de LA LeY No 19.175 (1989), Segundo Trámite Constitucional en el Senado, Primer Informe Comisión de Gobierno y de Constitución unidas, 26 de julio de 1992, Boletín 589-06, p. 506. [Fecha de visita: 27 de septiembre de 2013] Disponible en: http://www.google.cl/url? sa=t\&rct=j\&q=\&esrc=s\&frm=1\&source=web\&cd= 2\&ved=0CDAQFjAB\&url=http $\% 3 \mathrm{~A} \% 2 \mathrm{~F} \% 2$ Fwww.bcn.cl\%2Fobtienearchivo $\% 3$ Fid $\% 3$ Dr ecursoslegales\%2F10221.3\%2F12824\%2F1\%2FHL19175.pdf\&ei=YexKUp6EBIX69QTqu YCoDA\&usg=AFQjCNHMcaw5zeAJjxWNsztpGYF1AhQX4g 
Estimamos que un servicio público pueda forzar la concreción de todas sus resoluciones es un exceso, puesto que con lo anterior se difumina el carácter excepcional y calificado que emana de la concesión de la ejecución de oficio.

Así, a modo de ejemplo, la competencia cuyo propósito es "el cumplimiento de las resoluciones que dicte en el ejercicio de las atribuciones que le confiere el presente título" del director general de Aguas -artículo 138 del CA- ${ }^{92}$, se torna más que en una potestad que persigue un objetivo, en una finalidad en sí misma. De similar modo, existen cinco normas, cuyos titulares son otros órganos administrativos, afines a la recién transcrita.

De igual forma, en los casos que el objetivo de la autotutela es forzar al particular a someterse a tal o cual potestad fiscalizadora, como aquella que tiene por finalidad aplacar la "oposición para ejercer las funciones" de fiscalización del superintendente de Valores y Seguros -artículo 26, inciso final, Decreto Ley 3.538-93, carece de un bien jurídico que se deba satisfacer en forma inmediata. Conforme a la anterior complexión, hallamos doce disposiciones similares.

b) Visto que la autotutela ejecutiva escinde parte del debido proceso administrativo y judicial, en aras de un extraordinario bien jurídico, estimamos que solo será jurídicamente tolerable tal prescindencia si está especialmente justificada por el órgano que la pone en práctica. De este modo, tanto la formulación de la competencia por el legislador, como su ejecución por el órgano administrativo deben estar motivadas.

El ejercicio de una competencia de autotutela debe responder a circunstancias extraordinarias. Lo anterior se explica pues la ejecución de oficio es una institución que no es la regla general, de tal suerte que los eventos que den pábulo a su aplicación deberán ser peculiares. Por lo anterior, si existe otra competencia que converja a satisfacer idéntico bien jurídico, debe ser utilizada esta.

En este punto es relevante destacar que hay competencias que sí respetan el debido proceso, y que pueden aplicarse para lograr el mismo fin que las de ejecución de oficio. Así, a modo de ejemplo, un alcalde puede aplicar la competencia de autotutela de demoler "sin más trámite" -artícu-

92 En el mismo sentido se pronuncian las siguientes normas, que permiten aplicar todas las decisiones, en general: artículo 34 del DFL No 22, de 1959; artículo 2 letra c) de la Ley No 19.175; artículo 3o No 22 de la Ley No 18.410; artículo 19 de la Ley No 18.902; artículo 55 del DFL No 323, de 1931.

93 Misma disposición encontramos en: artículo 38 de la Ley No 20.551; artículo 28 de la Ley No 18.302, artículo 21, inciso cuarto, de la Ley No 18.362; artículos $5^{\circ}$ y 13 de la Ley No 18.755; artículo 20, inciso segundo, de la Ley No 18.168; artículo 26 del DFL No 2, de 1967; artículo 28, inciso cuarto, de la Ley No 20.417; artículo $1^{\circ}$ No 30 letra a) de la Ley No 20.434; artículo 60, inciso séptimo del CT; artículos 33 y 83, inciso segundo, del DFL No 850 de 1998; artículo 155 del CS; y artículo $8^{\circ}$ de la Ley 10.336. 
lo 156 del Decreto con Fuerza de Ley No 458-; y también puede demoler una propiedad, pero fundamentado en los artículos 150 a 155, preceptos que anteceden al ejercicio de la competencia un justo y racional procedimiento.

De igual modo, el SEREMI de Salud es competente para ejercer la potestad de clausurar sin que exista procedimiento alguno, motivado en el del artículo 178 del CS; asimismo tiene la atribución de clausurar en el artículo 171 del CS, norma que sí contempla un procedimiento administrativo previo y la posibilidad expresa de reclamar a la justicia.

Entonces, si hay otros medios jurídicos plausibles, no bastará con que la competencia sea puesta en práctica en virtud de circunstancias calificadas, a más el órgano administrativo deberá explicar, en los fundamentos de hecho y de derecho del acto, por qué su práctica no se justifica en una competencia ordinaria.

3.1.3) Es gracias a específicas normas especiales que, a ciertos órganos administrativos, se les atribuye la potestad de ejecutar de oficio los actos desfavorables que previamente emitieron. Las normas facultan desde ciertas autoridades o jefes superiores de servicio, hasta algunos órganos inferiores para tales efectos, esta última circunstancia apareja múltiples inconvenientes de cara a la seguridad jurídica.

Ciertas leyes conceden la facultad extraordinaria de autotutelar sus actos desfavorables previos a los directores o a los órganos ejecutivos unipersonales, de los siguientes servicios públicos: Dirección General de Aguas $^{94}$, Comisión de Energía Nuclear, Servicio Nacional de Geología y Minería, Servicio Agrícola y Ganadero, Corporación Nacional Forestal, Superintendencia de Servicios Sanitarios, de Valores y Seguros, y de Electricidad y Combustibles ${ }^{95}$.

De igual forma pero en menor medida, las normas confieren la antedicha potestad a ciertas autoridades constitucionalmente establecidas, y a algunos órganos de carácter directivo y desconcentrados. En el primer caso se encuentran el contralor general de la República, al ministro de Transportes y Telecomunicaciones, a los alcaldes, a los intendentes, y

94 En los casos de la aplicación de la coacción por: Dirección General de Aguas, Superintendente de Valores y Seguros, Ministro de Transportes y Telecomunicaciones, y Director de Vialidad; estos órganos solicitan a otro que ordene la aplicación de la fuerza pública.

95 Las referidas leyes que otorgan tales competencias son correlativamente: artículo 138 del CA; artículo 28 de la Ley $\mathrm{N}^{\circ} 18.302$; artículo 38 de la Ley $\mathrm{N}^{\circ} 20.551$; artículo $5^{\circ}$ de la Ley $\mathrm{N}^{\circ}$ 18.755; artículo 21, inciso cuarto, de la Ley $\mathrm{N}^{\circ} 18.362$; artículo 19 de la Ley $\mathrm{N}^{\circ}$ 18.902; artículo 26, inciso final, del DL $\mathrm{N}^{\circ} 3.538$; artículo $3 \mathrm{~N}^{\circ} 22$ de la Ley $\mathrm{N}^{\circ} 18.410$, y artículo 55 del DFL N³23 de 1931. 
gobernadores ${ }^{96-97}$, y en el segundo, el director de Vialidad, y los SEREMI de Salud ${ }^{98}$.

Finalmente, las leyes facultan para aplicar la fuerza a inspectores y fiscalizadores de los siguientes servicios públicos: Servicio Agrícola y Ganadero, Superintendencia del Medio Ambiente, Servicio Nacional de Pesca, Servicio de Impuestos Internos e Inspección del Trabajo. También se atribuye a Carabineros de Chile, y a las Fuerzas Armadas y de Orden, la potestad para aplicar la fuerza directamente, sin intermedio de otro órgano administrativo ${ }^{99}$.

Estimamos que el órgano a quien se debe atribuir la facultad de autotutela es al jefe superior de servicio, $u$ otro que se asimile a este. Al contrario, las potestades conferidas a un órgano fiscalizador o inspector, envuelven graves riesgos e inconvenientes jurídicos para el particular.

Lo anterior se explica ya que en la Administración del Estado chilena, las decisiones se adoptan por las autoridades y los jefes de servicio. La Ley No 18.575 ordena que los servicios públicos chilenos estarán "a cargo" de este órgano unipersonal, de índole ejecutiva -artículo 31-100.

Por lo antedicho la competencia excepcional de la autotutela ejecutiva, en cuanto se radica en el jefe superior de servicio, es coherente con la estructura de la Administración del Estado. Pero aún más, calza con otros criterios y principios que legitiman al jefe de servicio como órgano aplicador de la ejecución de oficio, esto son el de control y legitimidad del órgano decisor.

Se justifica que el superior jerárquico sea aquel que posea la competencia de solicitar la fuerza pública, puesto que los órganos superiores están sometidos al escrutinio público en el ejercicio de sus potestades y, en ciertos casos, son elegidos mediante un sistema garantiza el cumplimiento de los requisitos necesarios para desempañar su cargo ${ }^{101}$.

96 Existe un único caso en que se le otorga a subsecretario la facultad de coaccionar sus actos desfavorables previos, el caso es aquel del subsecretario de Telecomunicaciones, situado en el artículo 20, inciso segundo, de la Ley No 18.168.

97 Las normas que conceden la potestad de autotutela a estas autoridades son: artículo $8^{\circ}$ de la Ley $\mathrm{N}^{\circ} 10.336$; artículo $3^{\circ}$ terdecies de la Ley $\mathrm{N}^{\circ} 20.504$; artículo 156 y 161 del DFL No 458 de 1976; artículo 34 DFL $\mathrm{N}^{\circ} 22$, de 1959; artículo $2^{\circ}$ letra c) de la Ley $\mathrm{N}^{\circ} 19.175 \mathrm{y}$ artículo $4^{\circ}$ letra d) y h) Ley $\mathrm{N}^{\circ} 19.175$.

98 Las leyes de donde arrancan las potestades para estos órganos son respectivamente: artículos 33 y 83 inciso segundo DFL No 850 de 1997; y artículo 155 y 178 del CS.

99 Los órganos individualizados tienen, correlativamente esta atribución gracias al: artículo 13 de la Ley $\mathrm{N}^{\circ} 18.755$; artículo 28, inciso cuarto, Ley $\mathrm{N}^{\circ} 20.417$; artí́culo $1^{\circ} \mathrm{N}^{\circ} 30$ letra a) de la Ley No 20.434; artículo 60, inciso séptimo del CT; artículo 26 del DFL Nº 2, de 1967; artículo $2^{\circ}$, letra e) del Decreto Supremo No 1.086, de 1983; y artículo 115 Ley No 18.700 .

100 Esto se debe a que "la ley radica usualmente las atribuciones a poder jurídicos en el jerarca máximo del organismo de que se trata”, Sото Kloss (2009) 180.

101 Esto ocurrió gracias a la innovación a que dio lugar la Ley No 19.882 que "Regula nueva política de personal a los funcionarios públicos" que transformó el nombramiento de cargos por la confianza del Presidente de la República, a un sistema que responde a parámetros y 
Del mismo modo, al otorgarse la autotutela ejecutiva a los órganos superiores, automáticamente se dispensa a los afectados un recurso judicial en contra de las decisiones de los primeros, constituyendo una vía para revisar su juridicidad ${ }^{102}$.

De forma contraria, la radicación de la competencia de autotutela en órganos desconcentrados, que en su mayoría son parte de organismos descentralizados que ejercen actividad de policía, como los inspectores y fiscalizadores de los servicios públicos, no presenta las ventajas anteriores y a la vez conlleva diversas desventajas.

Las amenazas que apareja la desconcentración dice relación con la reducción del control de los actos autotutelares, y la disminución de la aptitud del órgano que ejerce la competencia. El peligro se revela porque, al concederse una atribución desconcentrada no procede el recurso jerárquico $^{103}$, ni la Contraloría podría revisarlas preventivamente, dado que no existirá un Decreto ni Resolución que pueda ser revisado.

procedimientos que apuntan a contener la arbitrariedad en la elección del individuo que lo desempeñará. Véanse artículos TRIGÉSIMO QUINTO a TRIGÉSIMO SÉPTIMO de la Ley No 19.882 .

102 En los casos que la ley entrega la competencia de la autotutela ejecutiva a un jefe superior de servicio o a una autoridad, a la sazón confiere a los eventuales afectados por sus decisiones, un recurso judicial en contra de aquellas. Así, se podrá reclamar en contra de la decisión de aplicar la fuerza del: director general de Aguas, en virtud del recurso judicial expresamente conferido por el artículo 137 del CA. De igual forma se conceden recursos judiciales, en leyes especiales en contra de las decisiones de los órganos superiores, que se exponen como ejemplos: director del Servicio Agrícola y Ganadero -artículo 27 de la Ley No 18.755-, superintendente de Servicios Sanitarios -artículo 32 de la Ley No 18.902-, superintendente de Valores y Seguros -artículo 44 del DL 3.538-, alcalde -artículo 151 de la Ley No 18.695-; superintendente de Electricidad y Combustibles -artículo 58 del DFL No 323 de 1931, del Ministerio de Hacienda-, superintendente del Medio Ambiente -artículo 56 de la Ley 20.417-, intendente -artículo 108 de la Ley No 19.175-, y del director de Vialidad -artículo 50 del DFL No 850-.

En algunos casos, la facultad de autotutela ejecutiva no puede ser controlada mediante un recurso especial -por lo que solo serían procedentes los recursos ordinarios y el Recurso de Protección-. Se omite el anterior resguardo, a modo de ejemplo, en el caso que se concede la facultad de autotutela ejecutiva al: contralor General de la República, pues "no procede recurso alguno"; SEREMI de Salud, respecto de la atribución del artículo 155 y 178 del CS; subsecretario de Telecomunicaciones, por el ejercicio de la competencia situada en el artículo 20, inciso segundo, de la Ley $\mathrm{N}^{\circ}$ 18.168; ministro de Transporte y Telecomunicaciones, ya que no se contempla un recurso especial en contra la decisión contenida en el artículo único, artículo $3^{\circ}$ terdecies de la Ley No 20.504; director ejecutivo de la Corporación $\mathrm{Na-}$ cional Forestal, respecto de la atribución ubicada en el artículo 21, inciso cuarto, de la Ley $\mathrm{N}^{\circ}$ 18.362; director del Servicio Nacional de Minería y Geología, por la potestad del artículo 38 de la Ley $\mathrm{N}^{\circ}$ 20.551; y del director de la Comisión Nacional de Energía, a propósito de la competencia del artículo 28 de la Ley No 18.302 .

103 Tal como lo constata la uniforme jurisprudencia administrativa, la que ha declarado que "no procede el recurso jerárquico previsto en la referida ley No 19.880 , cada vez que el legislador acude a la técnica de la desconcentración, radicando todo un sector de materias dentro de la órbita exclusiva de un órgano administrativo distinto del superior del servicio de que se trate". Dictamen No 44.455 de 2009 , de la Contraloría General de la República, así como también en los Dictámenes Ns 47.491, de 2005; 44.314, de 2007 y No 26.738, de 2009. 
Además es inconveniente conceder esta potestad a órganos desconcentrados ya que estos podrían no estar vinculados de forma estable y permanente al servicio en que ejercen sus funciones ${ }^{104}$, esta situación se ejemplifica con los funcionarios inspectores y fiscalizadores del Servicio Agrícola y Ganadero, quienes pueden servir sus cargos "ad honorem" 105 , siendo común el uso de esta figura ${ }^{106}$.

Por lo anterior, si bien aparece como justificada la atribución de la autotutela a los jefes de servicio, no parece adecuado radicar tal competencia en un órgano que es controlado jurídicamente en menor modo que el superior, y que no es el idóneo para el ejercicio de tal tarea.

\section{2) APLICACIÓN PRÁCTICA DE LA AUTOTUTELA EJECUTIVA}

Verificado ya que la heterotutela judicial es excepcionada por escasas normas que consagran la autotutela ejecutiva, del modo antes acotado, debemos determinar si estas salvedades normativas son aplicadas por los órganos administrativos.

El Derecho Administrativo se manifiesta por la constante aplicación de normas, de parte de las personas, autoridades y funcionarios administrativos. Es a través de la actividad administrativa que la teoría pasa a la práctica, de suerte tal que sin esta última la primera queda solo en un marco ideal ${ }^{107}$.

104 El personal fiscalizador del Servicio Agrícola y Ganadero, puede estar compuesto por personas contratadas a honorarios "los que podrán tener la calidad de agentes públicos para los efectos de lo dispuesto en el DL No 799 de 1974, para efectos de desempeñar labores de fiscalización (...)" (Ley No 20.461, "Ley de presupuestos del sector público para el año 2013", del Ministerio de Agricultura, Partida 13, Capítulo 04, Programa 01, Subtítulo 21, Glosa No 4). La antedicha excepción normativa entronca con la facultad del director Nacional del Servicio Agrícola y Ganadero de "contratar, transitoriamente y a honorarios, la prestación de servicios profesionales, técnicos y de expertos, como también a trabajadores, siempre y cuando se trate de funciones o trabajos que no sea posible realizar con el personal de planta" (artículo 7o, letra l) de la Ley No 18.755).

105 El personal fiscalizador del Servicio Agrícola y Ganadero, puede estar compuesto por personas nombradas "ad honorem", estos pueden ejercer sus competencias habiendo "cumplido con la Ley de Instrucción Básica obligatoria" (artículo $1^{\circ}$, punto I "requisitos para ser nombrado inspector ad-honorem", número 2, del Decreto Supremo No 146, del Ministerio de Agricultura, de 1991). Este mismo acto administrativo general señala que "Carabineros de Chile prestarán ayuda para hacer cumplir las disposiciones sobre caza, de conformidad a lo señalado a la Ley de Caza, su Reglamento y Decretos complementarios, a los inspectores adhonorem que lo soliciten, acreditando su identidad con el carnet correspondiente" (artículo $1^{\circ}$, punto III "obligaciones y atribuciones de los inspectores ad honorem, número $7^{\circ}$ ).

106 Habiéndose solicitado al Servicio Agrícola y Ganadero, con fecha 28.6.13, "conocer las resoluciones mediante las cuales (i) se han nombrado a inspectores o fiscalizadores "ad honorem" en el Servicio Agrícola y Ganadero (...) desde el año 2000 a la fecha”, y siendo respondida esta con fecha 8.8.13, sabemos que el antedicho servicio ha nombrado más de ciento noventa funcionario en esta calidad.

107 Alejandro Nieto señala "para una teoría realista del Derecho el análisis de las normas jurídicas no es más que el comienzo -convencional e incompleto- del estudio del Derecho, ya 
Entonces, para responder cómo se ha aplicado una norma, debemos atender a la esencia de nuestra disciplina, cual es la indagación empírica e inductiva de datos. Por lo anterior es que en este trabajo, al paso de haber ilustrado la realidad normativa, expondremos la efectiva aplicación de la autotutela ejecutiva.

Consecuente con lo anterior, nos cuestionamos ¿se aplica la autotutela ejecutiva en la realidad? Sí, se aplica. Para responder la antedicha pregunta se efectuaron, a través del artículo 10 de la Ley No 20.285, consultas a todos los servicios públicos que poseen las competencias especiales de autotutela ejecutiva ${ }^{108}$.

De los veintidós servicios que poseen la competencia de la autotutela ejecutiva, dieciocho respondieron a la solicitud de acceso a la información, entregando datos pertinentes al ejercicio de la autotutela. Del anterior universo, el 50\% -nueve organismos-, aseguraron que entre los ańos 2010 a 2013, no habían ejecutado la competencia de autotutela individualizada, al contrario 50\% -nueve organismos- señalaron que sí la habían aplicado.

Respecto de aquellos que sí utilizaron la autotutela ejecutiva, un $44.4 \%$-cuatro organismos- entregaron actos administrativos concretos en donde figuraba la ejecución de oficio. Los restantes organismos se remitieron a responder que sí la utilizaron $44.4 \%$-cuatro organismos-, o bien afirmaron que la ponían en práctica de forma verbal $11.1 \%$-un organismo-.

A la par, y a modo de ratificación de los datos encontrados, se efectuó el mismo cuestionamiento a la Policía de Investigaciones ${ }^{109}$ y a Cara-

que aquellas, por sí solas, no tienen valor ni sentido, que solo adquirirán a medida que se vayan ejecutando, aplicando y cumpliendo" Nieto, Alejandro (2007) Derecho Administrativo sancionador. $4^{\mathrm{a}}$ edición. Madrid: Editorial Tecnos, p. 127. A este respecto, véase su teoría de la realidad en el derecho, y específicamente en el Derecho Administrativo, pp. 81-151.

108 Se transcriben los servicios a los que se consultó, más la fecha de la solicitud de acceso a la información: con fecha 20.3.13, Superintendencia de Valores y Seguros, Gobernación de Valparaíso, Superintendencia de Electricidad y Combustibles, y Servicio de Impuestos Internos; con fecha 28.3.13, Servicio Nacional de Pesca; con fecha 5.4.13, Inspección del Trabajo, Intendencia Metropolitana, y Municipalidad de Puente Alto; con fecha 12.7.13, Dirección General de Aguas, Comisión Chilena de Energía Nuclear, Servicio Agrícola Ganadero, Superintendencia Servicios Sanitarios, Subsecretaría de Telecomunicaciones, SEREMI de Salud Metropolitano, y Dirección de Vialidad; con fecha 16.3.13, Contraloría General de la República; con fecha 5.9.13, Superintendencia de Medio Ambiente, Servicio Nacional de Geología y Minería; con fecha 11.9.13, Corporación Nacional Forestal; y con fecha 1.10.13, Carabineros de Chile, Ejercito de Chile y Ministerio de Transportes y Telecomunicaciones.

109 La Policía de Investigaciones respondió la consulta de fecha 20.3.13, mediante la que se solicitó "copia de todos los decretos, resoluciones u oficios y todos los actos administrativos, desde 1 de enero de 2010 hasta 1 de enero de 2013, en que cualquier organismo de la Administración del Estado haya solicitado sin resolución judicial, auxilio de la fuerza pública para cumplir un acto administrativo desfavorable a un particular”. En su réplica señaló que se habían cumplido 2.305 actos decisorios, en vista de que la Ley de Extranjería, el DL 
bineros de Chile ${ }^{110}$, en cuanto a la recepción de actos administrativos que delataran una orden de la Administración cuyo objeto fuere coaccionar a un particular.

De los anteriores datos podemos inferir que la autotutela ejecutiva es aplicada. Si bien no se utiliza de forma tan profusa como la heterotutela judicial $^{111}$, basta que solo un organismo administrativo la haya utilizado para que sea imperativo delimitar su ámbito de aplicación -véase capítulo III, punto 1.2.2-.

\section{CONCLUSIONES}

En Chile no existe una competencia genérica, fruto de la cual los órganos administrativos puedan arrogarse la majestad de aplicar coactivamente sus actos. En otras palabras, quienes sostienen que en nuestro

1.094, así se lo permitía. Estos actos, según nuestro parecer, no constituyen autotutela -véase capítulo III, punto 1.1.2.2-.

110 Carabineros de Chile se negó a responder la consulta efectuada con fecha 20.3.13, en la que se pedía "copia, de todos los decretos, resoluciones u oficios, y de todos los actos administrativos de cualquiera sea su denominación que, desde el día 1 de enero del año 2010 hasta el 1 de enero de 2013, en que cualquier órgano de la Administración del Estado hayan solicitado directamente, y sin intermedio de una resolución judicial, el auxilio de la fuerza pública para cumplir un acto administrativo desfavorable para un particular", puesto que "[...] no puede sino calificarse como un requerimiento referido a un elevado número de actos administrativos, y cuya atención, requiere distraer indebidamente a los funcionarios del cumplimiento regular de sus labores habituales". En vista de lo anterior, y a fin de facilitar la entrega de la información, se reformuló la consulta en dos ocasiones, acotando la solicitud a la Prefectura Oriente de Carabineros, desde el ańo 2012 hasta el 2013. Frente a la nueva negativa de Carabineros de Chile, con fecha 7.6.13, recurrimos al Consejo para la Transparencia -expediente rol No C-828-13, a fin de contar con la información, organismo administrativo acogió el amparo deducido. El Consejo para la Transparencia ordenó, con fecha 2.10.13, la entrega de la información, en lo relevante indicó que en el periodo consultado sí se solicitó el auxilio de la fuerza pública por la Administración del Estado. Estas alcanzan a "118 (...) órdenes efectuadas por la Intendencia Metropolitana y 21 por el Ministerio de Obras Públicas”. Consejo para la Transparencia. 2 de octubre de 2013. Rol N 828-13, considerando $4^{\circ}$. "Solicitud de amparo de María del Pilar Rodríguez con Carabineros de Chile”. Disponible en: http://extranet.cplt.cl/Web_SCW/Archivos/C828-13/C828-13_Decisión_Web.pdf [Fecha de visita 13 de noviembre de 2013]

111 La Administración no utiliza las competencias de modo tan abundante como lo hacen los tribunales de justicia, indicio de esto aparece en la decisión rol No C-828-13, del Consejo para la Transparencia, antes citada. El considerando $4^{\circ}$, en el que se aborda la cantidad de órdenes judiciales y administrativas de aplicación de la fuerza pública, que recibió Carabineros de Chile en un periodo de un año, señaló “(...) el organismo reclamado manifestó inicialmente que se trataba de un total de 9.876 órdenes que debía revisar, aumentando esa cantidad con ocasión de la gestión oficiosa decretada por este Consejo en un total de 39.045 documentos. Con todo, Carabineros de Chile aclaró que de estas últimas, solamente 118 corresponden a órdenes efectuadas por la Intendencia Metropolitana y 21 por el Ministerio de Obras Públicas, estableciendo que el resto corresponde a órdenes judiciales, las que no se encuentran incluidas en la solicitud (...)”. Consejo para la Transparencia. 2 de octubre de 2013. Rol N 828-I3. 
ordenamiento jurídico los actos administrativos son susceptibles de concretarse por la sola voluntad de la Administración del Estado, yerran en su diagnóstico. Lo antedicho se debe a que la teoría del derecho enuncia y las normas positivas concretan otra concepción, cual es que la heterotutela judicial se constituye en la regla general.

Todas las reglas, como fuentes jurídicas materiales concretas y específicas, se ejecutan en caso de que una de las partes se oponga su cumplimiento, a través de una sentencia proveniente de un tribunal de justicia. El acto administrativo sigue igual suerte: se hace ejecutar por los tribunales de justicia, en caso que el destinatario se niegue a realizarlo.

Calza con lo anterior que nuestro constituyente ni el legislador de la Ley No 19.880 hayan facultado a la Administración del Estado para ejecutar de oficio sus actos. Por una parte, la Constitución solo entregó tal competencia a los tribunales de justicia, y excepcionalmente a otros órganos, siempre en situaciones especiales, o bien sujetos a la "autorización judicial previa". De igual manera, la Ley No 19.880 no dispensa la autotutela ejecutiva a los órganos administrativos. Lo anterior se debe a la estructura y finalidad de la mencionada ley, el tenor literal de sus preceptos, la historia fidedigna de su establecimiento, y la diferencia en esta parte con la norma española que la inspiró.

Secuela de lo anterior es que el legislador, de forma casuística, haya consagrado excepcionalmente la autotutela ejecutiva. Definimos a esta como las excepciones legales que, en vista del desobedecimiento de un acto desfavorable o en virtud a una constatación de un órgano administrativo, permiten aplicar la fuerza pública u otra medida de coacción, sin mediar procedimiento alguno, con el fin de satisfacer específicos bienes jurídicos.

\section{BibLIOGRAFÍA}

- Abeliuk Manasevich, René (2005) Las obligaciones. 4a edición, Santiago: Editorial Jurídica de Chile, Tomo II, 796 pp.

- Aranis Merino, Sergio (1955) El principio de la ejecutoriedad del acto administrativo. Memoria de Prueba para optar al grado de Licenciado en Ciencias Jurídicas y Sociales. Santiago: Editorial Universitaria S.A., 83 pp.

- Aróstica Maldonado, Iván (1995) Lecciones Sobre Acto Administrativo. Santiago: Inédito/Facultad de Derecho de Universidad de Chile, Departamento de Derecho Público, 106 pp.

- Aylwin Azócar, Patricio (1952) Manual de Derecho Administrativo. Santiago: Editorial Jurídica de Chile, 325 pp.

- Bermúdez Soto, Jorge (2011) Derecho Administrativo General. Santiago: Editorial Legal Publishing, 603 pp. 
- Boвbio, Norberto (1987) Teoría General del Derecho. Traducción de Eduardo Rozo Acuña. Bogotá: Editorial Temis, 269 pp.

- Bocksang Hola, Gabriel (2006) El Procedimiento Administrativo Chileno: Estudio analitico y sistemático de coherencia. Santiago: Editorial LexisNexis, 234 pp.

- Boloña Kelly, Germán (2005) El Acto Administrativo. Santiago: Editorial LexisNexis, 321 pp.

- Caldera Delgado, Hugo (1981) El Acto Administrativo: Legalidad, efectos e impugnación. Santiago: Editorial Jurídica de Chile, 185 pp.

- Camacho, Gladys (2002) El Acto Administrativo. Santiago: Facultad de Derecho de Universidad de Chile, Departamento de Derecho Público, 35 pp.

- Casarino Viterbo, Mario (2007) Manual de Derecho Procesal, Derecho Procesal Orgánico. 6a edición. Santiago: Editorial Jurídica de Chile.

- Colombo Campbell, Juan (1991) La Jurisdicción en el Derecho Chileno. Santiago: Editorial Jurídica de Chile, 64 pp.

- Cordero Quincazara, Eduardo (sin fecha) "La eficacia, extinción y ejecución de los actos administrativos en la ley $\mathrm{N}^{\circ} 19.880$ ". En: Escuela de Derecho Universidad Católica de Valparaíso: Actas de las segundas jornadas de Derecho Administrativo, Santiago: Ediciones Universitarias de Valparaíso, pp. 109-130.

- Cordero Vega, Luis (2003) El procedimiento administrativo. Santiago: Editorial LexisNexis, 228 pp.

- Enteiche Rosales, Nicolás (2012) "Autorización judicial previa e impugnación supuesta de la actuación administrativa: nuevos elementos del debido proceso en la jurisprudencia del tribunal constitucional". Revista Ius et Praxis Universidad de Talca. Año 18 $\mathrm{N}^{\circ} 1$, pp. 427-438.

- Enteiche Rosales, Nicolás (2012) "Ley N² 20.322: Avances y desafíos respecto de la inspección y sanción de infracciones administrativas en materia tributaria". Revista Actualidad Jurídica. Año $2012 \mathrm{~N}^{\circ} 26$, pp. 259-278.

- Esteve Pardo, José (2011) Lecciones de Derecho Administrativo. Madrid: Editorial Marcial Pons, 581 pp.

- Ferrada Bórquez, Juan Carlos (2007) "Las potestades y privilegios de la administración pública en el régimen administrativo chileno". Revista de Derecho de la Universidad Austral de Chile (Valdivia), Vol. XX No 2, pp. 69-94.

- Fueyo Laneri, Fernando (2004) Cumplimiento e incumplimiento de las obligaciones. $3^{a}$ edición. Santiago: Editorial Jurídica de Chile, 650 pp.

- García De Enterría, Eduardo (2011) Curso de Derecho Administrativo I. 15a Edición. Navarra: Editorial Thomson Reuters, Tomo I. 
- Iribarren, Juan Antonio (1936) Lecciones de Derecho Administrativo. Santiago: Editorial Nascimento, 203 pp.

- Jara Cristi, Manuel (1943) Derecho Administrativo. Santiago: Impresores Artes y Letras, 854 pp.

- Kelsen, Hans (1982) Teoría Pura del Derecho. Traducción de Roberto J. Vernengo. México D.F: Universidad Nacional Autónoma de México, 358 pp.

- Madariaga Gutiérrez, Mónica (1965) Derecho Administrativo y Seguridad Jurídica. Santiago: Editorial Jurídica de Chile, 154 pp.

- Moraga Klenner, Claudio (2010) Tratado de Derecho Administrativo: La actividad formal de la administración del Estado. Santiago: Editorial LegalPublishing, 574 pp.

- Nieto, Alejandro (2007) Derecho Administrativo sancionador. 4a edición. Madrid: Editorial Tecnos, 591 pp.

- Oelkers Camus, Osvaldo (1978) "El principio de la autotutela administrativa como privilegio de la Administración Pública". Revista de Derecho de la Universidad Católica de Valparaíso, N², pp. 121-153

- Pantoja Bauzá, Rolando (1960) Concepto de Acto Administrativo. Santiago: Editorial Jurídica de Chile, pp. 1-93.

- Pantoja Bauzá, Rolando (1994) Leyes administrativas sobre municipalidades. Santiago: Editorial Jurídica de Chile, 314 pp.

- Ríos Álvarez, Lautaro (1985) El urbanismo y los principios fundamentales del derecho urbanistico. Tesis doctoral presentada por el autor en la Universidad Complutense de Madrid, 629 pp.

- Rodríguez Grez, Pablo (1999) El Derecho Como Creación Colectiva. Santiago: Ediciones Jurídicas, 281 pp.

- Sánchez Morón, Miguel (2011) Derecho Administrativo: Parte general. 6a edición. Madrid: Editorial Tecnos, 344 pp.

- Silva Cimma, Enrique (2001) Derecho Administrativo Chileno y Comparado: actos, contratos y bienes. Santiago: Editorial Jurídica de Chile. Volumen V, 336 pp.

- Soto Kloss, Eduardo (1978) La ejecución del acto administrativo (Suspensión y revocación). Bogotá: Colegio Mayor de Nuestra Señora del Rosario, pp. 1-33.

- Soto Kloss, Eduardo (2009) Derecho Administrativo: Temas Fundamentales. Santiago: Editorial LegalPublishing, 788 pp.

- Urzúa Ramírez, Carlos (1971) Requisitos del Acto Administrativo. Santiago: Editorial Jurídica de Chile, 112 pp.

\section{JURISPRUDENCIA}

- Consejo para la Transparencia. 2 de octubre de 2013. Rol N$^{\circ}$ 828-13. "Solicitud de amparo de María del Pilar Rodríguez con Carabineros de Chile". Disponible en: http://extranet.cplt.cl/Web_ 
SCW/Archivos/C828-13/C828-13_Decisión_Web.pdf [Fecha de visita 13 de noviembre de 2013]

- Corte de Apelaciones de Santiago. 7 de julio de 1999. Rol No 485-1998. "Tesorería Regional Metropolitana con Iván Patricio Sánchez Santibáńez". Gaceta Jurídica 229, Año 1999.

- Corte de Apelaciones de Punta Arenas. 7 de agosto de 2007. Rol No 164-2007. "Tesorería regional de Magallanes con deudores morosos". Disponible en: http://corte.poderjudicial.cl/ SITCORTEPORWEB/. [Fecha de visita 13 de septiembre de 2013]

- Corte de Apelaciones de Temuco. 21 de enero de 2010. Rol No I 864-2009. "Fisco de Chile con Pereira Jiménez Juana". Disponible en: http://corte.poderjudicial.cl/SITCORTEPORWEB/. [Fecha de visita 13 de septiembre de 2013]

- Tribunal Constitucional. 12 de julio de 2011. Rol N 1894. "Control de constitucionalidad del proyecto de ley que sanciona el acoso sexual de menores, la pornografía infantil y la posesión de material pornográfico infantil". Disponible en: http://www. tribunalconstitucional.cl/wp/ver.php?id=2011. [Fecha de visita $13 \mathrm{de}$ septiembre de 2013]

- Tribunal Constitucional. 16 de junio de 2003. Rol No 376. "Control de constitucionalidad respecto del proyecto de ley sobre transparencia, límite y control del gasto electoral”. Disponible en: http://www.tribunalconstitucional.cl/wp/ver.php?id=244 [Fecha de visita 13 de septiembre de 2013]

- Tribunal Constitucional. 21 de octubre de 2010. Rol No 1518. "Requerimiento de inaplicabilidad por inconstitucionalidad de María Angélica Sánchez Vogel y otros, respecto del artículo 169 del Código Sanitario". Disponible en: http://www. tribunalconstitucional.cl/wp/ver.php?id=1587. [Fecha de visita 13 de septiembre de 2013]

- Tribunal Constitucional. 15 de marzo de 2011. Rol No 1912. "Control de constitucionalidad del proyecto de ley aprobado por el Congreso Nacional que modifica el régimen jurídico del transporte público concesionado". Disponible en: http://www. tribunalconstitucional.cl/wp/expedientes. [Fecha de visita 13 de Septiembre de 2013]

- Tribunal Constitucional. 26 de enero de 2011. Rol No 1580. "Requerimiento de inaplicabilidad por inconstitucionalidad presentado por Farmacias Cruz Verde S.A. respecto del inciso tercero del artículo 474 del Código del Trabajo". Disponible en: http:// www.tribunalconstitucional.cl/wp/ver.php?id=1759. [Fecha de visita 13 de septiembre de 2013] 


\section{OTROS}

- Comisión de Estudios de la Nueva Constitución (1977) "Sesión $\mathrm{N}^{\circ} 301^{\mathrm{a}}$, 28 de junio de 1977". Disponible: en: http://www. bcn.cl/lc/cpolitica/constitucion_politica/Actas_comision_ortuzar/ Tomo_IX_Comision_Ortuzar.pdf [Fecha de consulta: 27 de septiembre de 2013]

- Historia de la Ley No 19.880 (2003). Disponible en: https://www. google.cl/url?sa $=\mathrm{t} \& \mathrm{rct}=\mathrm{j} \& \mathrm{q}=\&$ esrc $=\mathrm{s} \&$ source $=\mathrm{web} \& \mathrm{~cd}=1 \& \mathrm{cad}=\mathrm{rja} \&$ ved=0CC0QFjAA\&url=http\%3A\%2F\%2Fwww.leychile.cl\%2FNave gar\%2Fscripts\%2Fobtienearchivo\%3Fid\%3Drecursoslegales\%2F102 21.3\%2F500\%2F1\%2FHL19880.pdf\&ei=XRILUuqwHPfi4AP_hY D4Cg\&usg=AFQjCNGyATpAoEQw15IogRiuBrQ5KXcLFA\&bvm =bv. 53371865,d.dmg [Fecha de visita 27 de Septiembre de 2013]

- $\quad$-Historia de la Ley No 19.175 (1989). Disponible en: http://www. google.cl/url? sa $=t \& r c t=j \& q=\&$ esrc $=s \& f r m=1 \&$ source $=w e b \& c d=2 \&$ ved=0CDAQFjAB\&url=http $\% 3 \mathrm{~A} \% 2 \mathrm{~F} \% 2 \mathrm{Fwww} \cdot \mathrm{bcn} . \mathrm{cl} \% 2 \mathrm{Fobtiene}$ archivo $\% 3$ Fid $\% 3$ Drecursoslegales $\% 2 \mathrm{~F} 10221.3 \% 2 \mathrm{~F} 12824 \% 2 \mathrm{~F} 1 \%$ 2FHL19175.pdf\&ei=YexKUp6EBIX69QTquYCoDA\&usg=AFQj CNHMcaw5zeAJjxWNsztpGYF1AhQX4g, [Fecha de visita: 27 de Septiembre de 2013]

- Historia de la Ley No 18.961 (1989). "Oficio del "Secretario de Legislación de la Junta de Gobierno", en el que se "Informa Proyecto de Ley Orgánica Constitucional de Carabineros”, Boletín N 1.20602

- Proyecto de Ley Boletín no 683-06 (1993), Disponible en: http:// www.senado.cl/appsenado/index.php?mo=sesionessala $\& a c=$ getDocu mento\&teseid $=23465 \&$ legiid $=183$ 